\title{
Article
}

\section{Synthetic flavonoid derivatives targeting the glycogen phosphorylase inhibitor site: QM/MM-PBSA motivated synthesis of substituted 5,7-dihydroxyflavones, crystallography, in vitro kinetics and ex- vivo cellular experiments reveal novel potent inhibitors}

Chetter, Ben, Kyriakis, Efthimios, Barr, Daniel, Karra, Aikaterini G., Katsidou, Elisabeth, Koulas, Symeon M., Skamnaki, Vassiliki T., Snape, Timothy James, Psarra, Anna-Maria G., Leonidas, Demetres D. and Hayes, Joseph

Available at http://clok.uclan.ac.uk/33666/

Chetter, Ben, Kyriakis, Efthimios, Barr, Daniel, Karra, Aikaterini G., Katsidou, Elisabeth, Koulas, Symeon M., Skamnaki, Vassiliki T., Snape, Timothy James ORCID: 0000-0003-2766-4491, Psarra, Anna-Maria G. et al (2020) Synthetic flavonoid derivatives targeting the glycogen phosphorylase inhibitor site: QM/MM-PBSA motivated synthesis of substituted 5,7-dihydroxyflavones, crystallography, in vitro kinetics and ex-vivo cellular experiments reveal novel potent inhibitors. Bioorganic Chemistry, 102 (104003). ISSN 0045-2068

It is advisable to refer to the publisher's version if you intend to cite from the work. http://dx.doi.org/10.1016/j.bioorg.2020.104003

For more information about UCLan's research in this area go to http://www.uclan.ac.uk/researchgroups/ and search for <name of research Group>.

For information about Research generally at UCLan please go to http://www.uclan.ac.uk/research/ 


\section{CLoK}

Central Lancashire online Knowledge www.clok.uclan.ac.uk 


\section{Synthetic flavonoid derivatives targeting the glycogen phosphorylase}

\section{inhibitor site: QM/MM-PBSA motivated synthesis of substituted 5,7-}

dihydroxyflavones, crystallography, in vitro kinetics and ex-vivo cellular

\section{experiments reveal novel potent inhibitors}

Ben A. Chetter, ${ }^{\text {a\# }}$ Efthimios Kyriakis, ${ }^{\text {b\# }}$ Daniel Barr, ${ }^{\text {a\# }}$ Aikaterini G. Karra, ${ }^{\text {b Elisabeth }}$

Katsidou, ${ }^{\mathrm{b}}$ Symeon M. Koulas, ${ }^{\mathrm{b}}$ Vassiliki T. Skamnaki, ${ }^{\mathrm{b}}$ Timothy J. Snape, ${ }^{* \mathrm{c}}$ Anna-Maria G. Psarra $^{* b}$, Demetres D. Leonidas, ${ }^{* b}$ Joseph M. Hayes*c

a School of Physical Sciences \& Computing, University of Central Lancashire, Preston PR1 2HE, United Kingdom

${ }^{\mathrm{b}}$ Department of Biochemistry \& Biotechnology, University of Thessaly, Biopolis, 41500

Larissa, Greece

${ }^{c}$ School of Pharmacy \& Biomedical Sciences, University of Central Lancashire, Preston PRI

2HE, United Kingdom

\footnotetext{
* Corresponding authors tel: +441772894334 (JMH), fax: +441772894981; email: jhayes@uclan.ac.uk tel: +302410565278 (DDL), fax: +302410565290; email: ddleonidas@ bio.uth.gr tel: +302410565221 (AMP), fax: +302410565290; email: ampsarra@bio.uth.gr tel: +441772895805 (TJS), fax: +441772894981; email: tjsnape@uclan.ac.uk ${ }^{\#}$ Equal contribution.
} 


\begin{abstract}
Glycogen phosphorylase (GP) is an important target for the development of new antihyperglycaemic agents. Flavonoids are novel inhibitors of GP, but their mode of action is unspecific in terms of the GP binding sites involved. Towards design of synthetic flavonoid analogues acting specifically at the inhibitor site and to exploit the site's hydrophobic pocket, chrysin has been employed as a lead compound for the in silico screening of 1169 new analogues with different $\mathrm{B}$ ring substitutions. QM/MM-PBSA binding free energy calculations guided the final selection of eight compounds, subsequently synthesised using a BakerVenkataraman rearrangement-cyclisation approach. Kinetics experiments against rabbit muscle $\mathrm{GPa}$ and $\mathrm{GPb}$ together with human liver $\mathrm{GPa}$, revealed three of these compounds (11, 20 and 43) among the most potent that bind at the site ( $K_{i} s<4 \mu \mathrm{M}$ for all three isoforms), and more potent than previously reported natural flavonoid inhibitors. Multiple inhibition studies revealed binding exclusively at the inhibitor site. The binding is synergistic with glucose suggesting that inhibition could be regulated by blood glucose levels and would decrease as normoglycaemia is achieved. Compound $\mathbf{4 3}$ was an effective inhibitor of glycogenolysis in hepatocytes $\left(I C_{50}=70 \mu \mathrm{M}\right)$, further promoting these compounds for optimization of their druglike potential. X-ray crystallography studies revealed the B-ring interactions responsible for the observed potencies.
\end{abstract}

Keywords: Flavonoids; halogens; natural products; QM/MM-PBSA; X-ray crystallography; type 2 diabetes. 


\section{Introduction}

Type 2 Diabetes (T2D) is a chronic heterogeneous disease characterised by hyperglycaemia. Its prevalence has been rising rapidly, but particularly in low- and middle-income countries [1]. T2D is characterized as a disorder of insulin secretion, insulin resistance and by increased production of hepatic glucose. Glycogenolysis may account for more than $70 \%$ of the hepatic glucose production. Additionally, a substantial amount of glucose from gluconeogenesis is cycled through the glycogen pool prior to efflux from the liver cells [2,3]. The rate-determining enzyme in the glycogenolysis pathway is glycogen phosphorylase (GP; EC 2.4.1.1), rendering GP a very promising and validated target for the development of much needed more effective T2D treatments [4]. However, GP inhibition has also been recognised as having significant potential for the treatment of other conditions such as cancer, myocardial and cerebral ischemias [5-7].

GP is an allosteric enzyme and has a number of different binding sites [8]: the catalytic, allosteric, new allosteric, inhibitor, quercetin binding,[9] benzimidazole[10] and the glycogen storage sites. It exists in two interconvertible forms, the phosphorylated GPa form which is the predominantly active $\mathrm{R}$ state and with high substrate affinity, and the unphosphorylated $\mathrm{GPb}$ form which is the predominantly inactive $\mathrm{T}$ state (low substrate affinity) [4]. Phytogenic chemicals are a promising source of compounds with the potential to inhibit GP $[11,12]$. Natural flavonoids have been revealed as a good source of GP inhibitors in a number of studies [13-16], which have recently been reviewed $[11,12]$. They are ubiquitous components of fruit and vegetables and are consumed in our daily diets. Significantly, studies in diabetic and nondiabetic rats have shown that the anti-hyperglycaemic properties of flavonoids are due to their effect on glycogen metabolism [17-19]. Jakobs et al. extensive study of 24 flavonoids demonstrated that most of the compounds investigated inhibited rabbit muscle GPa (rmGPa), and that inhibition of GPa was two to four times better than for rmGPb [13]. This inhibition of the active GPa form is favourable in terms of potential for blood glucose regulation in T2D patients.

Structurally, flavonoids have a general scaffold consisting of two aromatic rings (A and B), linked by three carbon atoms that are usually in a heterocyclic ring (C) with oxygen (c.f. chrysin, Figure 1). The differences in ring $\mathrm{C}$ leads to the structural classification of flavonoids as flavones, flavanols, flavanones, anthocyanidins and isoflavonoids [11]. The best flavonoid inhibitors of GP are on the low $\mu \mathrm{M}$ range, some of which are shown in Figure 1. These include 
the flavonols quercetin and quercetagetin; flavones such as 6-hydroxyluteolin and chrysin. Certain anthocyanidins such as cyanadin and catechins such as epigallocatechin gallate (EGCG), are also potent inhibitors. However, the inhibitory potential of different flavonoids is very sensitive to the substitution patterns within the different structural classes [11].<smiles>O=c1cc(-c2ccccc2)oc2cc(O)cc(O)c12</smiles>

Chrysin

$\mathrm{IC}_{50}(\mathrm{GPa})=27.5[13]$

$\mathrm{IC}_{50}(\mathrm{GPb})=15.3[13],(19.01$

$\left.\left(K_{i}\right)\right)[16]$

Binding site: inhibitor site<smiles>O=c1cc(-c2ccc(O)c(O)c2)oc2cc(O)c(O)c(O)c12</smiles>

6-hydroxyluteolin $\mathrm{IC}_{50}(\mathrm{GPb})=11.6[13]$

Binding site: unknown<smiles>CN1CCC(c2c(O)cc(O)c3c2OC(c2ccccc2Cl)=CC3O)C(O)C1</smiles>

Flavopiridol

$\mathrm{K}_{\mathrm{i}}(\mathrm{GPb})=1.16[21], 1.24[16]$ Binding site: inhibitor site<smiles>O=c1c(O)c(-c2ccc(O)c(O)c2)oc2cc(O)cc(O)c12</smiles>

quercetin

$\mathrm{IC}_{50}(\mathrm{GPa})=4.8$ [13]

$\mathrm{IC}_{50}(\mathrm{GPb})=20.9$ [13], 33.5 [14]

Binding site: quercetin [9]<smiles>Oc1cc(O)c2cc(O)c(-c3ccc(O)c(O)c3)[o+]c2c1</smiles>

cyanidin

$\mathrm{IC}_{50}(\mathrm{GPa})=3.0$ [13]

$\mathrm{IC}_{50}(\mathrm{GPb})=9.0[13]$

Binding site: unknown<smiles>CN1CC=C(c2c(O)cc(O)c3c2OC(c2ccccc2)=CC3O)CC1</smiles>

flavopiridol analogue

$\mathrm{K}_{\mathrm{i}}(\mathrm{GPb})=1.28[22]$

Binding site: inhibitor site*<smiles>O=c1c(O)c(-c2ccc(O)c(O)c2)oc2cc(O)c(O)c(O)c12</smiles>

quercetagetin

$\mathrm{IC}_{50}(\mathrm{GPb})=9.7$ [14], $\left(3.5\left(\mathrm{~K}_{\mathrm{i}}\right)\right)$ [14]

Binding site: allosteric<smiles>O=C(O[C@H]1Cc2c(O)cc(O)cc2O[C@H]1c1cc(O)c(O)c(O)c1)c1cc(O)c(O)c(O)c1</smiles>

EGCG

$\mathrm{IC}_{50}(\mathrm{GPa})=7.7[13]$

$\mathrm{IC}_{50}(\mathrm{GPb})=33.9$ [13], 34.0 [20]

Binding site: unknown<smiles>CN1CC=C(c2c(O)cc(O)c3c2OC(c2cccc(Cl)c2)=CC3O)CC1</smiles>

flavopiridol analogue

$\mathrm{K}_{\mathrm{i}}(\mathrm{GPb})=0.83[22]$

Binding site: inhibitor site* 


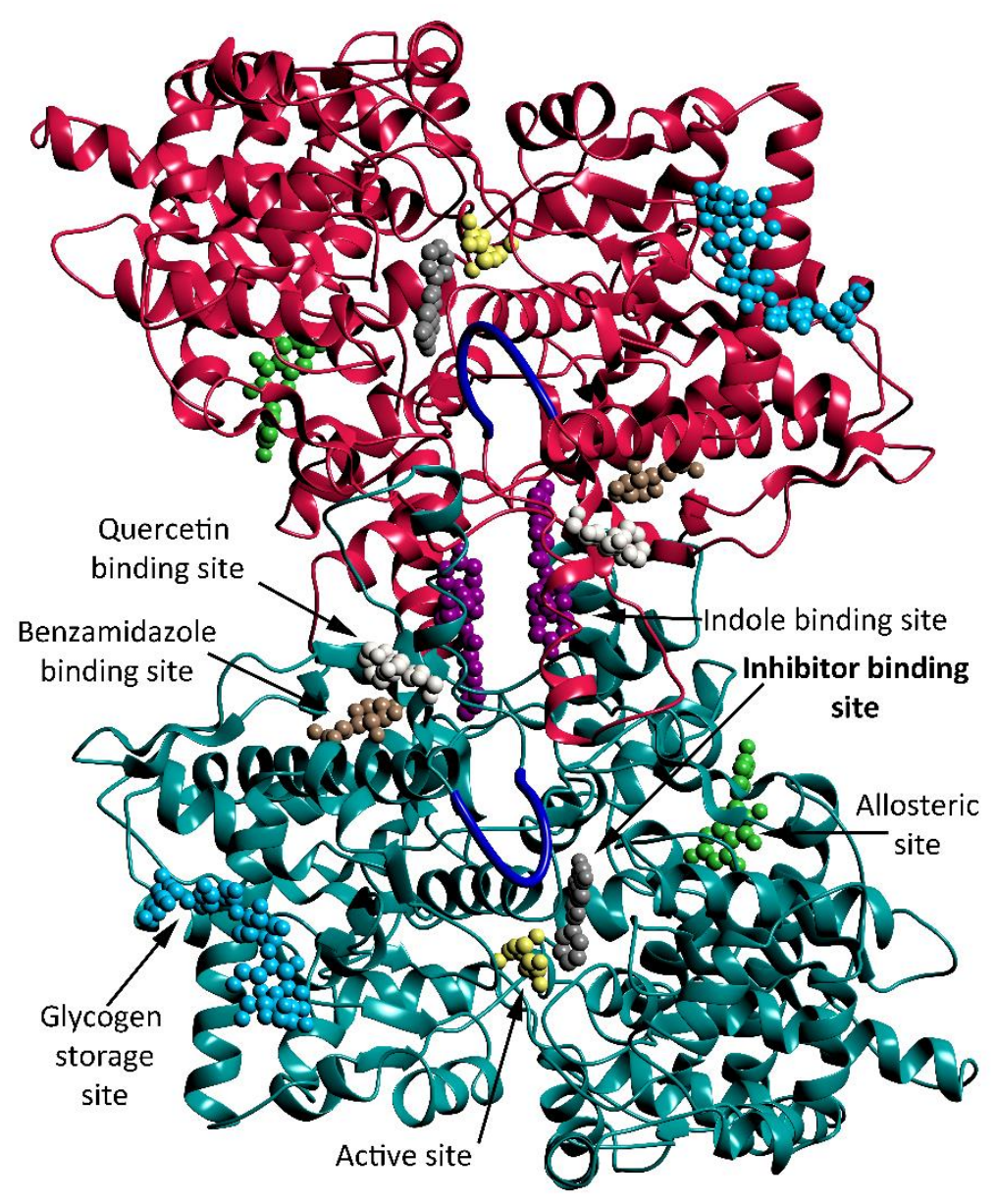

Figure 1. Inhibition constants $(\mu \mathrm{M})$ for some of the most potent natural flavonoid inhibitors of glycogen phosphorylase known to date together with their inhibition data and binding sites. The flavonoid ring labels A-C and atom numbering scheme used throughout text is shown for chrysin. Also displayed is the synthetic flavonoid derivative flavopiridol, together with two of its analogues. (* $=$ assumed binding site). The GPb dimer is also shown with the various binding sites indicated.

Previously it was assumed that flavonoids may display their inhibitory potential of GP by a similar mode of action. However, it is now evident from recent studies [9, 14-16] that their binding site is dependent on the flavonoid specific substitution patterns, more specifically the presence or absence of different hydroxyl groups. Indeed, the GP binding site of most flavonoids is unknown [11]. However, the binding of chrysin to GP has been studied in detail; its solved crystal structure complex with $\mathrm{rmGPb}$ revealed binding exclusively at the inhibitor site [16].

The inhibitor site of GP, also known as the caffeine $\left(K_{i} \sim 0.1 \mathrm{mM}[23,24]\right)$ binding site, is found on the surface of the enzyme, approximately $12 \AA$ from the catalytic site. When the enzyme is in the less active T state, Phe285, from the 280s loop (residues 282-287) is stacked close to Tyr613, from the $\alpha 19$ helix (residues 613-631). These two aromatic residues form the 
core of the inhibitor site. The ligands that bind to this site are considerably influenced by these residues due to the potential for an inhibitor to form a sandwich-like complex with GP, exploiting $\pi$-stacking interactions with both Phe285 and the Tyr613 sidechains (Fig. 2). This promotes the $\mathrm{T}$ state conformation of the enzyme via stabilisation of the closed conformation of the 280s loop, which in turn blocks access to the catalytic site. Inhibition of the binding site generally acts synergistically with glucose, which suggests that inhibition could be regulated by blood glucose levels, and would decrease as normoglycaemia is achieved without causing hypoglycaemia.[25] Because of this property, design of inhibitors targeting the site is particularly attractive from a drug design perspective. The most potent reported inhibitor binding at the site is flavopiridol (Figure $1 ; K_{i} \sim 1.2 \mu \mathrm{M}[16,21]$ ) with slightly better inhibition obtained in a study of its analogues (best $K_{i}=0.83 \mu \mathrm{M}$ ) [22]. Natural products such as flavonoids provide scaffolds for design of potent GP inhibitors but the only flavonoid ligand confirmed to bind at the site is chrysin, with a previously reported $K_{i}$ of $19.01 \mu \mathrm{M}$ [16].

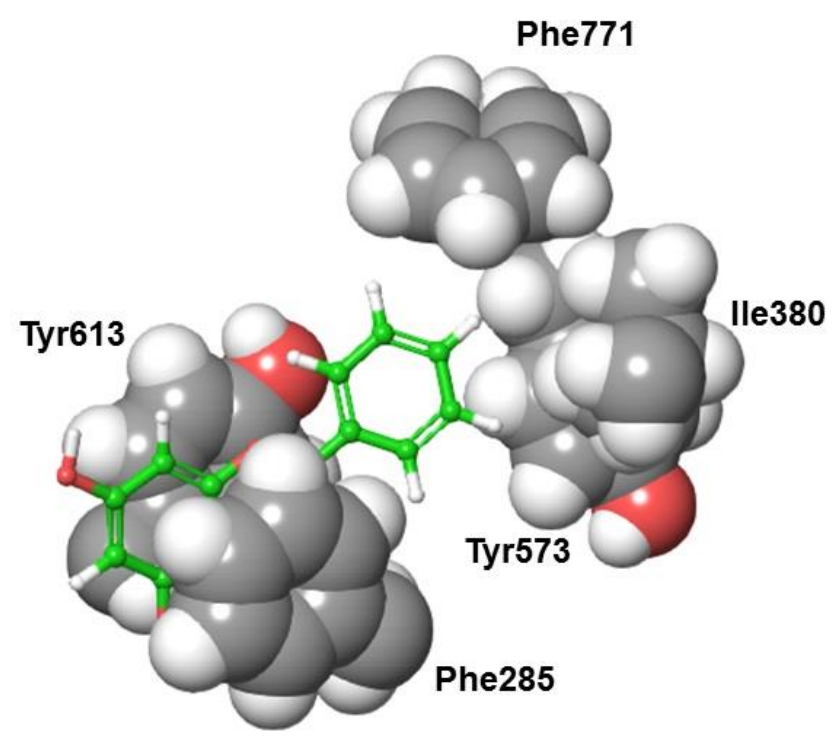

Figure 2. Binding of chrysin at the inhibitor site of rmGPb (PDB entry: $3 E B O[16])$ highlighting the key $\pi$-stacking interactions involved with residues Phe285 and Tyr613 and also the hydrophobic pocket key residues Ile380, Tyr573 and Phe771 in close proximity to the phenyl ring $\mathrm{B}$ of chrysin.

Of particular importance to binding of flavonoids at this site is a hydrophobic pocket lined by Ile380, Tyr573 and Phe771, as highlighted in Fig. 2. We have previously proposed that flavonoids with ring B polar $\mathrm{OH}$ substituents (in particular at position 4') are unfavourable for inhibitor site binding on the basis of quantum mechanics - molecular mechanics/Poisson Boltzmann surface area (QM/MM-PBSA) binding free energy (BFE; $\left.\Delta G_{\text {bind }}\right)$ calculations 
[16]. It was demonstrated that quercetagetin with 3' and 4' OH substituents (Fig. 1) displayed poor binding at the site based on its calculated binding affinity, and this was in agreement with multiple inhibition studies proposing allosteric site binding [14]. This theory was further validated by the subsequent discovery of the quercetin binding site (PDB entry 4MRA) discovered through the screening of polyphenolic extracts from the vinification byproducts of Vitis vinifera [9]. These binding features have motivated the current work to design more potent synthetic flavonoid analogues of the lead compound chrysin with different ring B that act specifically at the inhibitor site.

In this paper, we present the virtual screening of a library of 1169 compounds exploiting the ZINC database (http://zinc.docking.org)[26] using chrysin as the lead compound and its 7dihydroxy-4H-chromen-4-one moiety as the core scaffold for the design of more effective B ring substituents (Fig. 3). Initial screening was performed using Glide docking [27] in both standard (Glide-SP) and extra precision (Glide-XP) modes but combining the results in a consensus approach both in terms of predicted binding affinities [28, 29] and binding modes [30], aimed at reducing the number of false positive predictions. The top-ranked predicted compounds considered to be synthetically viable were then post-processed using QM/MMPBSA binding free energy calculations. Eight candidates were selected for synthesis and extensive kinetics studies performed. Crystallographic studies revealed the interactions that govern the observed potencies. Additionally, the effectiveness of the most potent inhibitor for reduction of glycogenolysis at the cellular level was explored. 
<smiles>O=c1ccoc2cc(O)cc(O)c12</smiles>

5,7-dihydroxy-4H-chromen-4-one core

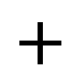

CombiGlide<smiles>[R]c1ccc(-c2cc(=O)c3c(O)cc(O)cc3o2)cc1</smiles>

Benzoyl chloride substructure

(1169 structures)<smiles>[R]c1ccc(C(=O)Cl)cc1</smiles> 
approach predicted 79 and 257 analogues as more potent than chrysin using models 1 and 2, respectively. As anticipated, model 2 allowed larger substituents on the B ring to occupy a more open hydrophobic pocket.

End point methods such as MM-PB(GB)SA are an effective post-docking strategy for the calculation of binding free energies [31]. QM/MM-PB(GB)SA methods, however, are gaining more prominence due to potential for better description of binding site interactions using QM methods [32-35], and have previously been successfully applied to flavonoid binding at the GP inhibitor site where a QM description was necessary to describe the $\pi$-stacking interactions of ligands with residues Phe285 and Tyr613 [16]. Here, preliminary QM/MM-PBSA calculations on the top-ranked 200 ligands from docking for each of model 1 and model 2 were performed. Protein-ligand complex geometries that gave $\Delta G_{\text {bind }}$ values $<-11 \mathrm{kcal} / \mathrm{mol}$ (a threshold chosen based on its proximity to the $\Delta G_{\text {bind }}$ value of $-12.35 \mathrm{kcal} / \mathrm{mol}$ for chrysin) were refined using Prime 4.2 [27] (58 ligands) before a final set of QM/MM-PBSA binding free energy calculations. As expected, the final $\Delta G_{\text {bind }}$ values were lower for these optimized complex structures and 36 analogues were predicted as more potent than the lead compound chrysin ($14.12 \mathrm{kcal} / \mathrm{mol}$ ) (Table 1$)$.

Analysis of the 36 flavonoid derivatives in Table 1 revealed 12, 22 and 2 ligands having mono, di- and tri-substituted B rings, respectively. These substitutions are mainly in the B ring ortho (21 ligands) and meta (25 ligands) positions, with 10 ligands having para substitutions. The majority of substitutions are with halogens (28 ligands), particularly with fluorine (15 ligands). 5 ligands have di-fluoro B ring substitutions. Fluorine is widely used in the lead optimization phase of drug design projects due to its potential to enhance drug-like properties such as permeability [36]. This has particular significance for flavonoids where oral bioavailability remains one of the most critical issues for their role in nutrition and health [37]. 10, 9 and 2 derivatives contained one $\mathrm{Cl}, \mathrm{Br}$ or I substituent, respectively. A smaller size halogen, therefore, appeared to be potentially more favourable. One compound had di-chloro substitutions (meta- and para-positions). Other B ring substituents for the 36 compounds were methyl (2 ligands), amine (2 ligands), aldehyde ( $\mathrm{CHO}$ ) group (1 ligand) and hydroxyl (7 ligands).

Analysing the breakdown of $\Delta G_{\text {bind }}$ (Eq.(1); c.f. Experimental Section) for the top 36 ligands (Table 1), the $\Delta E_{Q M / M M}$ values representing the gas phase interaction energy values dominate with values between -55.03 and $-79.51 \mathrm{kcal} / \mathrm{mol}$. The strongest $\Delta E_{Q M / M M}$ interactions 
(compound 16) have polar hydroxyl groups in the 2' and 3' positions; the corresponding least favourable (compound 29) has fluorine at the meta positions ( 3 ' and 5 '). For ligands that are halogen substituted only, the best $\Delta E_{Q M / M M}$ values are $-60.71 \mathrm{kcal} / \mathrm{mol}$ for compound $\mathbf{1 0}$ with fluorine (3') and bromine (4') substitutions, and $-59.63 \mathrm{kcal} / \mathrm{mol}$ for compound 11 with fluorine (3') and chlorine (4') substitutions. However, more favourable $\Delta E_{Q M / M M}$ values generally had less favourable solvation free energy changes $\left(\Delta G_{\text {solv }}\right)$ values (range of $+21.23-+45.77$ $\mathrm{kcal} / \mathrm{mol}$ ). The larger desolvation penalties were associated with the more polar groups, as demonstrated by the larger polar contributions to the solvation free energy changes $\left(\Delta G_{\text {solv }}^{P B}\right.$ term, predominantly electrostatic solvation enthalpy effects). $\Delta G_{\text {solv }}^{P B}$ values ranged from +26.09 (compound 1) to $+50.38 \mathrm{kcal} / \mathrm{mol}$ (compound 16). Meanwhile, the non-polar contributions $\left(\Delta G_{\text {Solv }}^{S A}\right)$ to the solvation free energy changes were small and similar for all ligands (range $-4.39--5.11 \mathrm{kcal} / \mathrm{mol}$ ). A sensitive balance between $\Delta E_{Q M / M M}$ and $\Delta G_{\text {solv }}$ for the identification of new potent inhibitors was therefore observed. For example, compound 16 with 2' and 3' $\mathrm{OH}$ substitutions had the most favourable $\Delta E_{Q M / M M}$ value $(-79.51 \mathrm{kcal} / \mathrm{mol})$ but the least favourable $\Delta G_{\text {solv }}$ value $(+45.77 \mathrm{kcal} / \mathrm{mol})$ and was ranked sixteen; ligand (1) with a 4' $\mathrm{Br}$ substitution had the least desolvation penalty $\left(\Delta G_{\text {solv }}=21.23 \mathrm{kcal} / \mathrm{mol}\right)$ but much less favourable $\Delta E_{Q M / M M}$ value $(-59.29 \mathrm{kcal} / \mathrm{mol})$ yet was ranked first. Entropy changes, $T \Delta S$, on the other hand had a range of just $\sim 2 \mathrm{kcal} / \mathrm{mol}(-13.37$ to $-15.99 \mathrm{kcal} / \mathrm{mol})$ and did not influence as much the ligand rankings.

Considering synthetic viability as well as the availability of reagents, eight compounds were selected for synthesis and subsequent experimental validation, none of which gave warnings for Pan Assay Interference Compounds (PAINS) [38], as determined using the ZINC on-line filter (http://zinc15.docking.org/patterns/home/). Predicted inhibitors ranked 1 (4' $=\mathrm{Br}$ ) and 2 $\left(2^{\prime}=\mathrm{OH}\right)$ were chosen, together with fluoro-substituted $9\left(3^{\prime}=\mathrm{F}\right)$ and $\mathbf{2 0}\left(4^{\prime}=\mathrm{F}\right)$. Two disubstituted ligands ranked $\mathbf{1 0}\left(3^{\prime}=\mathrm{Br} ; 4^{\prime}=\mathrm{F}\right)$, and $\mathbf{1 1}\left(3^{\prime}=\mathrm{Cl} ; 4^{\prime}=\mathrm{F}\right)$ were also selected. Although not in the top 36, we additionally chose two other mono-substituted ligands with methyl substituents in the meta 3' (43) and para 4' positions (52). Their $\Delta G_{\text {bind }}$ values were $13.47 \mathrm{kcal} / \mathrm{mol}$ and $-12.01 \mathrm{kcal} / \mathrm{mol}$, respectively. They were ranked in $\sim$ the top 50 from an initial 1169 ligands and their simple non-polar substituents considered to have potential to exploit the hydrophobic cavity from visual inspection of the predicted complexes. 
Table 1: QM/MM-PBSA results showing the breakdown of contributions to $\Delta G_{b i n d} \cdot{ }^{\text {a }}$

\begin{tabular}{|c|c|c|c|c|c|c|c|c|c|c|c|}
\hline \multirow[t]{2}{*}{$\begin{array}{l}\text { Ligand } \\
/ \text { rank }^{\mathrm{b}}\end{array}$} & \multicolumn{5}{|c|}{${ }^{\prime \prime}{ }^{\prime}$} & \multicolumn{6}{|c|}{$\begin{array}{c}\text { QM/MM-PBSA } \\
(\mathrm{kcal} / \mathrm{mol})\end{array}$} \\
\hline & 2 ' & 3 ' & $4^{\prime}$ & 5 & 6 ' & $\Delta E_{Q M / M M}$ & $\Delta G_{\text {solv }}^{P B}$ & $\Delta G_{\text {solv }}^{\text {SA }}$ & $\Delta G_{\text {solv }}^{\text {total }}$ & $T \Delta S$ & $\Delta G_{\text {bind }}$ \\
\hline $1 *$ & $\mathrm{H}$ & $\mathrm{H}$ & $\mathrm{Br}$ & $\mathrm{H}$ & $\mathrm{H}$ & -59.29 & 26.09 & -4.86 & 21.23 & -14.69 & -23.37 \\
\hline $2 *$ & $\mathrm{OH}$ & $\mathrm{H}$ & $\mathrm{H}$ & $\mathrm{H}$ & $\mathrm{H}$ & -70.83 & 38.18 & -4.78 & 33.40 & -14.69 & -22.74 \\
\hline 3 & $\mathrm{Cl}$ & $\mathrm{H}$ & $\mathrm{H}$ & $\mathrm{H}$ & $\mathrm{H}$ & -57.88 & 27.20 & -4.98 & 22.21 & -13.85 & -21.82 \\
\hline 4 & $\mathrm{~F}$ & $\mathrm{H}$ & $\mathrm{H}$ & $\mathrm{Br}$ & $\mathrm{H}$ & -59.96 & 28.66 & -4.93 & 23.73 & -14.73 & -21.50 \\
\hline 5 & $\mathrm{OH}$ & $\mathrm{CH}_{3}$ & $\mathrm{H}$ & $\mathrm{H}$ & $\mathrm{H}$ & -65.72 & 34.82 & -4.96 & 29.86 & -14.96 & -20.89 \\
\hline 6 & $\mathrm{NH}_{2}$ & $\mathrm{H}$ & $\mathrm{H}$ & $\mathrm{Cl}$ & $\mathrm{H}$ & -65.65 & 35.80 & -4.58 & 31.22 & -15.14 & -19.29 \\
\hline 7 & $\mathrm{Br}$ & $\mathrm{H}$ & $\mathrm{H}$ & $\mathrm{H}$ & $\mathrm{H}$ & -59.07 & 30.53 & -4.55 & 25.98 & -13.90 & -19.18 \\
\hline 8 & $\mathrm{~F}$ & $\mathrm{H}$ & $\mathrm{Cl}$ & $\mathrm{H}$ & $\mathrm{H}$ & -57.08 & 28.14 & -4.69 & 23.45 & -14.49 & -19.13 \\
\hline 9* & $\mathrm{H}$ & $\mathrm{F}$ & $\mathrm{H}$ & $\mathrm{H}$ & $\mathrm{H}$ & -56.08 & 28.45 & -4.76 & 23.69 & -13.37 & -19.02 \\
\hline $10 *$ & $\mathrm{H}$ & $\mathrm{Br}$ & $\mathrm{F}$ & $\mathrm{H}$ & $\mathrm{H}$ & -60.71 & 32.43 & -5.14 & 27.29 & -14.55 & -18.87 \\
\hline $11 *$ & $\mathrm{H}$ & $\mathrm{Cl}$ & $\mathrm{F}$ & $\mathrm{H}$ & $\mathrm{H}$ & -59.63 & 31.45 & -4.79 & 26.66 & -14.24 & -18.73 \\
\hline 12 & $\mathrm{~F}$ & $\mathrm{H}$ & $\mathrm{F}$ & $\mathrm{H}$ & $\mathrm{H}$ & -57.21 & 29.59 & -4.47 & 25.13 & -13.69 & -18.39 \\
\hline 13 & $\mathrm{~F}$ & $\mathrm{H}$ & $\mathrm{H}$ & $\mathrm{I}$ & $\mathrm{H}$ & -57.34 & 29.39 & -5.06 & 24.33 & -14.63 & -18.38 \\
\hline 14 & $\mathrm{~F}$ & $\mathrm{H}$ & $\mathrm{H}$ & $\mathrm{Cl}$ & $\mathrm{H}$ & -57.07 & 29.55 & -4.95 & 24.60 & -14.32 & -18.15 \\
\hline 15 & $\mathrm{OH}$ & $\mathrm{H}$ & $\mathrm{H}$ & $\mathrm{Cl}$ & $\mathrm{H}$ & -71.17 & 43.26 & -5.11 & 38.15 & -15.24 & -17.78 \\
\hline 16 & $\mathrm{OH}$ & $\mathrm{OH}$ & $\mathrm{H}$ & $\mathrm{H}$ & $\mathrm{H}$ & -79.51 & 50.38 & -4.61 & 45.77 & -15.99 & -17.74 \\
\hline 17 & $\mathrm{H}$ & $\mathrm{Cl}$ & $\mathrm{Cl}$ & $\mathrm{H}$ & $\mathrm{H}$ & -59.11 & 32.04 & -4.91 & 27.13 & -14.79 & -17.19 \\
\hline 18 & $\mathrm{H}$ & $\mathrm{Cl}$ & $\mathrm{H}$ & $\mathrm{H}$ & $\mathrm{H}$ & -56.89 & 30.59 & -4.94 & 25.66 & -14.11 & -17.12 \\
\hline 19 & $\mathrm{H}$ & $\mathrm{NH}_{2}$ & $\mathrm{H}$ & $\mathrm{H}$ & $\mathrm{H}$ & -59.52 & 32.78 & $\begin{array}{l}-4.69 \\
\end{array}$ & 28.09 & -14.42 & -17.01 \\
\hline 20* & $\mathrm{H}$ & $\mathrm{H}$ & $\mathrm{F}$ & $\mathrm{H}$ & $\mathrm{H}$ & -59.04 & 32.80 & -4.76 & 28.04 & -14.07 & -16.93 \\
\hline 21 & $\mathrm{H}$ & $\mathrm{Br}$ & $\mathrm{H}$ & $\mathrm{F}$ & $\mathrm{H}$ & -56.32 & 29.18 & -4.42 & 24.76 & -14.64 & -16.92 \\
\hline 22 & $\mathrm{H}$ & $\mathrm{Br}$ & $\mathrm{H}$ & $\mathrm{H}$ & $\mathrm{H}$ & -57.31 & 31.07 & -4.76 & 26.31 & -14.11 & -16.89 \\
\hline 23 & $\mathrm{~F}$ & $\mathrm{H}$ & $\mathrm{H}$ & $\mathrm{H}$ & $\mathrm{H}$ & -56.43 & 30.63 & -4.39 & 26.24 & -13.64 & -16.54 \\
\hline 24 & $\mathrm{H}$ & $\mathrm{F}$ & $\mathrm{F}$ & $\mathrm{H}$ & $\mathrm{H}$ & -58.70 & 33.86 & -5.03 & 28.83 & -14.00 & -15.87 \\
\hline 25 & $\mathrm{~F}$ & $\mathrm{Br}$ & $\mathrm{H}$ & $\mathrm{H}$ & $\mathrm{H}$ & -56.23 & 30.86 & -4.73 & 26.13 & -14.33 & -15.76 \\
\hline 26 & $\mathrm{OH}$ & $\mathrm{H}$ & $\mathrm{Cl}$ & $\mathrm{H}$ & $\mathrm{H}$ & -71.56 & 45.10 & -4.62 & 40.48 & -15.43 & -15.65 \\
\hline 27 & $\mathrm{H}$ & $\mathrm{OH}$ & $\mathrm{H}$ & $\mathrm{OH}$ & $\mathrm{H}$ & -71.88 & 46.16 & -4.67 & 41.49 & -14.86 & -15.53 \\
\hline 28 & $\mathrm{~F}$ & $\mathrm{H}$ & $\mathrm{H}$ & $\mathrm{Br}$ & $\mathrm{F}$ & -55.13 & 30.35 & -4.92 & 25.43 & -14.43 & -15.27 \\
\hline 29 & $\mathrm{H}$ & $\mathrm{F}$ & $\mathrm{H}$ & $\mathrm{F}$ & $\mathrm{H}$ & -55.03 & 30.39 & -4.60 & 25.79 & -14.20 & -15.03 \\
\hline 30 & $\mathrm{~F}$ & $\mathrm{H}$ & $\mathrm{F}$ & $\mathrm{CH}_{3}$ & $\mathrm{H}$ & -59.81 & 34.58 & -4.96 & 29.62 & -15.33 & -14.87 \\
\hline 31 & $\mathrm{~F}$ & $\mathrm{H}$ & $\mathrm{H}$ & $\mathrm{F}$ & $\mathrm{H}$ & -56.20 & 32.22 & -4.86 & 27.36 & -13.98 & -14.86 \\
\hline 32 & $\mathrm{Cl}$ & $\mathrm{H}$ & $\mathrm{H}$ & $\mathrm{Br}$ & $\mathrm{H}$ & -58.38 & 33.94 & -4.85 & 29.09 & -14.64 & -14.65 \\
\hline 33 & $\mathrm{H}$ & $\mathrm{OH}$ & $\mathrm{H}$ & $\mathrm{H}$ & $\mathrm{H}$ & -70.06 & 45.21 & -4.67 & 40.54 & -15.07 & -14.45 \\
\hline 34 & $\mathrm{CHO}$ & $\mathrm{H}$ & $\mathrm{H}$ & $\mathrm{H}$ & $\mathrm{H}$ & -58.52 & 34.48 & -4.67 & 29.81 & -14.36 & -14.36 \\
\hline 35 & $\mathrm{~F}$ & $\mathrm{Cl}$ & $\mathrm{H}$ & $\mathrm{H}$ & $\mathrm{H}$ & -55.62 & 31.98 & -4.92 & 27.06 & -14.27 & -14.29 \\
\hline 36 & $\mathrm{H}$ & I & $\mathrm{H}$ & $\mathrm{H}$ & $\mathrm{H}$ & -57.39 & 33.50 & -4.71 & 28.79 & -14.34 & -14.25 \\
\hline
\end{tabular}




\begin{tabular}{|l|c|c|c|c|c|c|c|c|c|c|c|}
\hline $\mathbf{3 7}$ & $\boldsymbol{H}$ & $\boldsymbol{H}$ & $\boldsymbol{H}$ & $\boldsymbol{H}$ & $\boldsymbol{H}$ & $\mathbf{- 5 6 . 2 4}$ & $\mathbf{3 3 . 3 0}$ & $\mathbf{- 4 . 8 2}$ & $\mathbf{2 8 . 4 8}$ & $\mathbf{- 1 3 . 6 4}$ & $\mathbf{- 1 4 . 1 2}$ \\
\hline $\mathbf{4 3}^{*}$ & $\mathrm{H}$ & $\mathrm{CH}_{3}$ & $\mathrm{H}$ & $\mathrm{H}$ & $\mathrm{H}$ & -57.77 & 34.64 & -4.86 & 29.78 & -14.52 & -13.47 \\
\hline $\mathbf{5 2}$ & $\mathrm{H}$ & $\mathrm{H}$ & $\mathrm{CH}_{3}$ & $\mathrm{H}$ & $\mathrm{H}$ & -50.53 & 28.42 & -4.59 & 23.83 & -14.68 & -12.01 \\
\hline
\end{tabular}

${ }^{a}$ c.f. Eq.'s (1) and (2). Chrysin is highlighted in bold italics and the eight ligands selected for synthesis highlighted with an asterisk (*). ${ }^{\mathrm{b}}$ Compounds were numbered by rank of predicted $\Delta G_{\text {bind }}$.

\subsection{Synthesis}

In general, compounds 1, 9, 10, 11, 20, 43 and 52 were synthesised in four steps (Scheme 1) from commercially available starting materials. The synthetic process started with a union between 2'-hydroxy-4',6'-dimethoxyacetophenone (A) and the benzoyl chloride of choice identified from the CombiGlide results $(\mathbf{B})$, to yield ester $(\mathbf{C})$ in good yields. A base-promoted Baker-Venkataraman rearrangement followed in which the aroyl group migrated from oxygen onto carbon giving rise to diketone (D). An acid catalysed cyclization reaction yielded the core flavonoid structure $(\mathbf{E})$, which following demethylation, gave the desired products $(\mathbf{F})$. For the synthesis of compound $2\left(\mathrm{R}=2^{\prime}-\mathrm{OH}\right)$, the same sequence of steps were repeated (Scheme 1$)$, but instead of using 2'-hydroxy-4',6'-dimethoxyacetophenone (A), 2'-hydroxyacetophenone was used instead for a reaction with 2,4,6-trimethoxybenzoyl chloride. In this latter case, compound $\mathbf{G}$ was isolated as the product of step 3, which after treatment with hydroiodic $\mathrm{acid} / \mathrm{PhOH}$ under reflux then resulted in de-methylation followed by a ring-opening/ringclosing isomerisation to provide compound $2\left(\mathrm{R}=2^{\prime}-\mathrm{OH}\right)$.

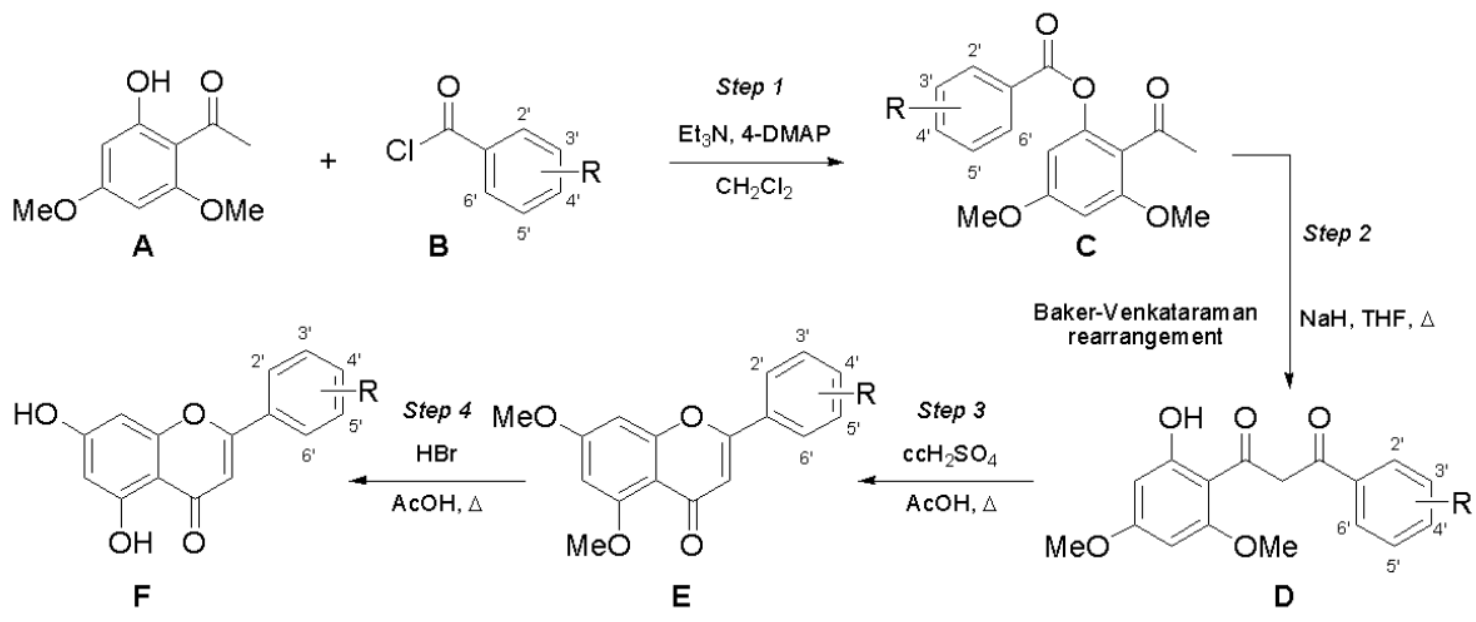
1, $\mathrm{R}=4^{\prime}-\mathrm{Br}$
9, $R=3^{\prime}-F$
10, $\mathrm{R}=3^{\prime}-\mathrm{Br}, 4^{\prime}-\mathrm{F}$
11, $\mathrm{R}=3^{\prime}-\mathrm{Cl}, 4^{\prime}-\mathrm{F}$
20, $\mathrm{R}=4^{\prime}-\mathrm{F}$
43, $\mathrm{R}=3^{\prime}-\mathrm{CH}_{3}$
52, $\mathrm{R}=4^{\prime}-\mathrm{CH}_{3}$

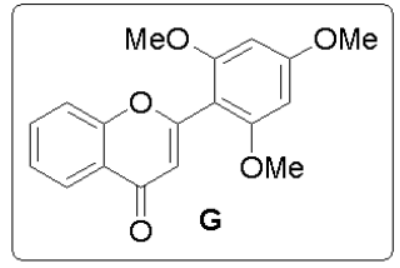

For the synthesis of compound $2\left(\mathrm{R}=2^{\prime}-\mathrm{OH}\right)$, steps $1-3$ above were repeated using 2,4,6-trimethoxybenzoyl chloride and 2 -hydroxyacetophenone which gave $\mathbf{G}$ as the product of step 3 . Treatment of $\mathbf{G}$ with hydroiodic acid/PhOH under reflux then resulted in de-methylation followed by a ring-opening/ring-closing isomerisation to provide $\mathbf{F}(\mathrm{R}=2$ '-OH) 
Scheme 1. Synthesis of the eight substituted 5,7-dihydroxyflavones analogues tested.

\subsection{Kinetics}

The inhibitory potency of $1,2,9,10,11,20,43$ and 52 was assessed against human liver GPa (hlGPa; the pharmaceutical target), and rmGPa and rmGPb for comparison reasons to the structural studies (performed with $\mathrm{rmGPb}$ ). Since the $K_{\mathrm{i}}$ of quercetin has not been reported and the $K_{\mathrm{i}}$ of chrysin was reported for the glycogen breakdown [16], we determined the inhibition constants for these compounds against all three enzymes for comparison. All results are presented in Table 2. Quercetin displays a preference for rmGPa over $\mathrm{rmGPb}$, as suggested previously by the $I C_{50}$ values [13], but it is not as significant as implied (2-fold vs 5-fold). Nevertheless, quercetin is almost equipotent for rmGPa and hlGPa. Compounds $\mathbf{1}, \mathbf{2}$, and $\mathbf{1 0}$ displayed only $14-27 \%$ inhibition at $100 \mu \mathrm{M}$ for $\mathrm{rmGPb}$ and thus, we did not perform any further kinetic studies due to the observed weak inhibition.

To establish the binding site of $\mathbf{9}, \mathbf{1 1}, \mathbf{2 0}, \mathbf{4 3}$ and 52, the inhibition behaviour of the five compounds was investigated with respect to caffeine (inhibitor site) and AMP (allosteric site). The kinetic data were analysed by Dixon plots from which the interaction constant $(\alpha)$ between multiple inhibitors can be estimated [39]. Thus, with varying concentrations of caffeine and $\mathbf{9}$, 11, 20, 43 or 52, and constant concentrations of AMP (1 mM) and substrate (Glc-1-P; $20 \mathrm{mM})$ the Dixon plots, yielded a pattern of parallel lines (interaction constant approaches infinity), indicating that the binding of $9, \mathbf{1 1}, \mathbf{2 0}, \mathbf{4 3}$ or 52 and caffeine is mutually exclusive (i.e. each one competes with caffeine for the same binding site) [39]. Similar experiments with AMP and constant concentrations of Glc-1-P (2.5 mM) yielded intersected lines in the Dixon plots, signifying that $9, \mathbf{1 1}, \mathbf{2 0}, \mathbf{4 3}$ or 52 and AMP are not mutually exclusive (each of the inhibitors and AMP can simultaneously bind at the enzyme) [39]. These experiments indicated that all of the compounds $(\mathbf{9}, \mathbf{1 1}, \mathbf{2 0}, \mathbf{4 3}$ and 52) bind to the inhibitor binding site. Compounds 11, 20 and 43 are significantly more potent inhibitors than quercetin and chrysin, with $K_{\mathrm{i}}$ values in the range of lower $\mu \mathrm{M}$ ( $<4 \mu \mathrm{M}$ for all isoforms), while $\mathbf{9}$ is equipotent to chrysin (Table 2). $\mathbf{5 2}$ is more potent than quercetin but less potent than chrysin. $\mathbf{4 3}$ is the most potent of the designed compounds and the second most potent inhibitor reported for the inhibitor site of GP, while 11 and $\mathbf{2 0}$ are almost equipotent and also among the most potent compounds discovered to date. 
We then investigated whether the binding of the most potent inhibitor 43 to $\mathrm{GPb}$ interacts with that of glucose, like caffeine [40] which displays an interaction constant $\alpha=0.2$. Initial velocity studies were performed by varying $\mathbf{4 3}$ and glucose concentrations at fixed concentrations of the substrates Glc-1-P (2.5 mM) and glycogen (0.2\%). Plotting 1/v vs glucose concentration for various 43 concentrations yields a set of lines intersecting at the left of the y axis (Fig. S4). The binding of $\mathbf{4 3}$ interacts with glucose in a synergistic manner $(\alpha=0.65)$. Thus, $\mathbf{4 3}$ and glucose are able to bind to the enzyme at the same time [39], while each compound promotes the binding of the other, like caffeine and glucose [40] or ellagic acid and glucose [41].

Comparing the phenyl B ring substitutions (Table 2), it seems that a halogen atom at position 3 ' confers to inhibition with chlorine being the best, followed closely by fluorine, but a larger bromine (10) diminishes inhibitory potency. Position 4' seems to have a significant impact, and a fluorine atom at this position increases potency (11 and 20), while a methyl group (52) has a somewhat negative effect, but again a bromine diminishes potency (1). Finally, a single methyl group at the 3' (or 5') position for $\mathbf{4 3}$ leads to the most potent inhibitor of all compounds studied here. The inhibitory potency of the compounds seems to follow the same pattern for the three enzymes (i.e. $K_{\mathrm{i}}$ values for $\mathrm{hlGPa}>\mathrm{rmGPa}>\mathrm{rmGPb}$ ).

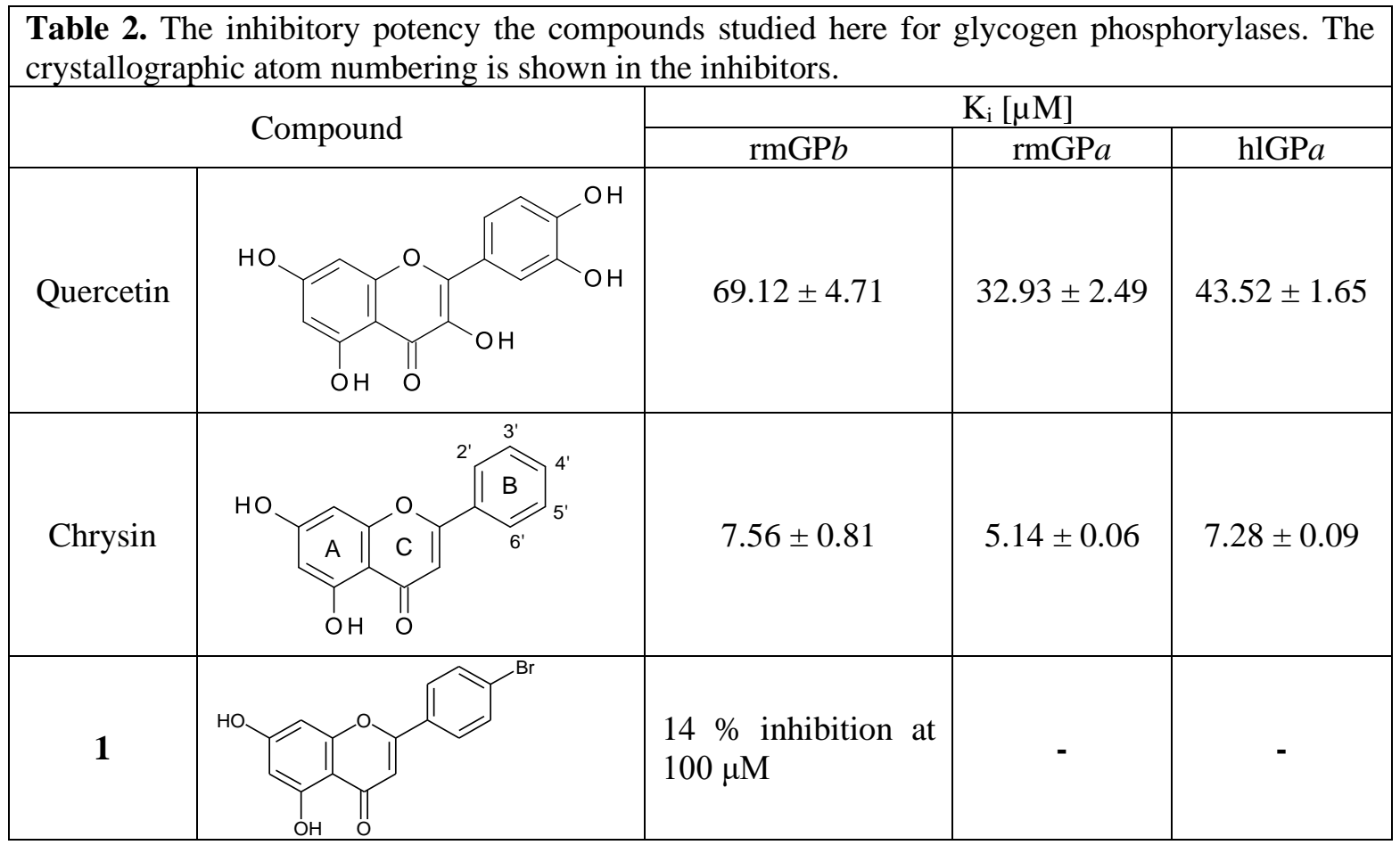




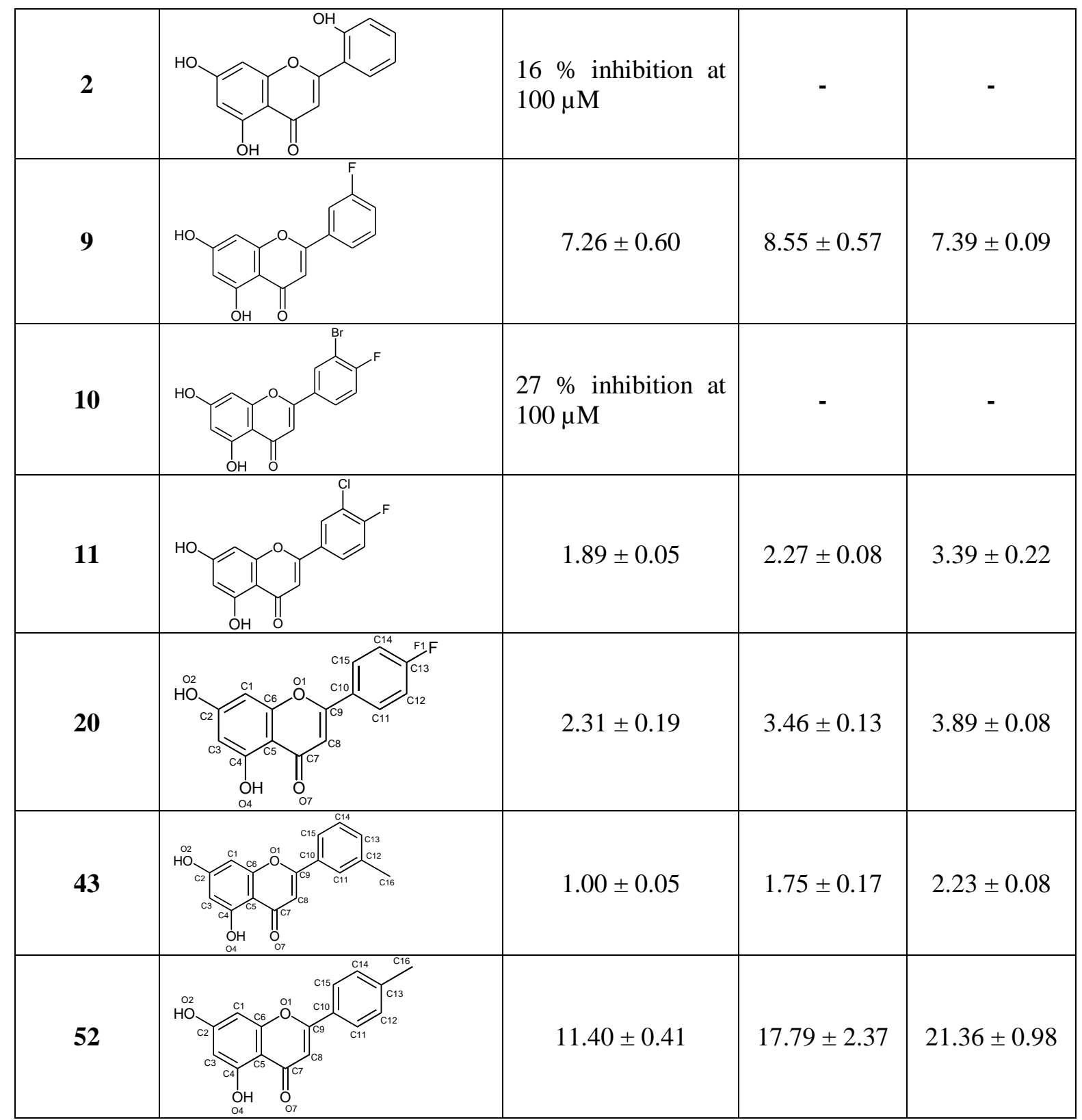

\subsection{X-ray Crystallography}

The crystal structures of rmGPb in complex with 20,43 and 52 were determined to elucidate the structural basis for their strong inhibition potency. Rabbit muscle and human liver GP share 97\% sequence homology and both enzymes are fully conserved in terms of sequence and structure at the inhibitor binding site, thus any structural analysis on rmGPb can also apply for hlGPa. All three compounds were found bound, as expected, at the inhibitor site of the enzyme with all their atoms well defined within the electron density maps (Fig. 4). All three inhibitors bind very similar. Their binding modes are also similar to those of chrysin [16] and flavopiridol [21]. The RMSD of $0.8 \AA$ between the free rmGPb structure and those of $\mathbf{2 0 ,} \mathbf{4 3}$ and $\mathbf{5 2}$ 
complexes with $\mathrm{GPb}$, for all atoms of well-defined residues (18-249, 262-312, 326-829), indicates that the binding of the inhibitors does not trigger any significant conformational change.
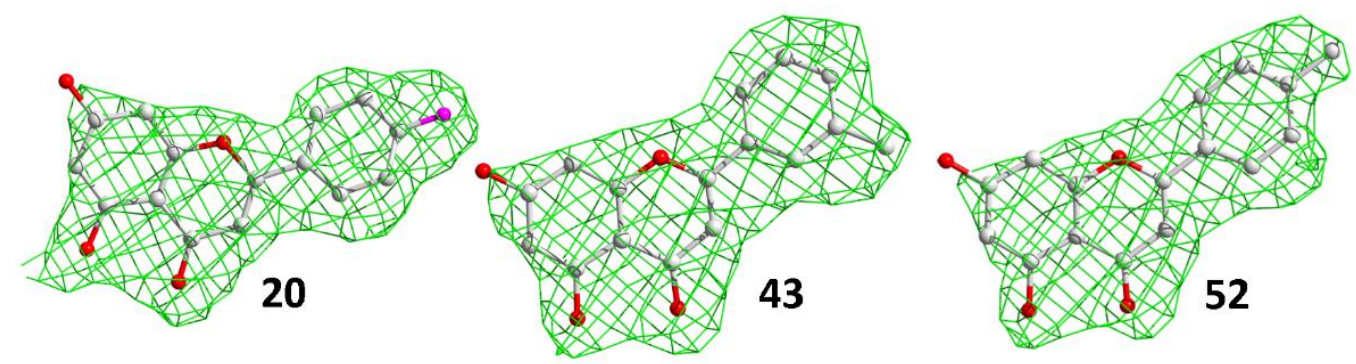

Figure 4. The Phenix polder omit difference electron density maps [42] of the ligands at the inhibitor site. Maps are contoured at $3.0 \sigma$ while the final models of the inhibitors are shown.

The $\mathrm{A}$ and $\mathrm{C}$ rings (Table 2) are packed between the aromatic side-chain phenyls of Phe285 and Tyr613 engaging in $\pi$-stacking (parallel) interactions. Para-fluorine atom of 20 is at distances of 3.1 and $3.2 \AA$ from Arg770 (NH1) and Glu382 (OE2), respectively, forming two fluorine bonds [43]. In all of the three inhibitor complexes, the hydroxyl group (O4) of the inhibitor molecule (Table 2), engages in two water mediated interactions with the main chain nitrogen atoms of Pro611 and Gly612, while the carbonyl oxygen (O7) forms two water mediated interactions with the main chain carbonyl oxygen and nitrogen of Asp283 (Fig. 5). Overall, 20 is involved in 101 (58 nonpolar/nonpolar, 6 polar/polar, 37 nonpolar/polar) van der Waals interactions mainly with Phe285 and Tyr613 (64 contacts), and with Asn282, Glu382, His571, Ala610, Gly612, and Arg770. 43 forms 91 (58 nonpolar/nonpolar, 4 polar/polar, 29 nonpolar/polar) van der Waals interactions mainly with Phe285 and Tyr613 (64 contacts), and with Asn282, Asn284, Glu382, Glu572, Ala610, Gly612, and Arg770. 52 engages in 89 (55 nonpolar/nonpolar, 4 polar/polar, 30 nonpolar/polar) van der Waals interactions mainly with Phe285 and Tyr613 (59 contacts), and with Asn282, Asn284, Glu382, His571, Glu572, Ala610, Gly612, Arg770, and Phe771 (Fig. 5). The solvent accessibilities of the free 20, $\mathbf{4 3}$ and $\mathbf{5 2}$ are 432, 450, and $448 \AA^{2}$, respectively. When bound these values become 83, 88, and $91 \AA^{2}$ indicating that approximately $80 \%$ of their surface area becomes inaccessible to the solvent. The greatest contribution comes favorably from the non-polar rmGPb residues that contribute $77 \%, 81 \%$, and $86 \%$ of the protein surface which becomes inaccessible upon binding of $\mathbf{2 0 , 4 3}$ and 52, respectively. The fluorine atom of $\mathbf{2 0}$ is involved in 7 ( 2 polar/polar, 5 polar/non-polar) van der Waals interactions with Glu382, Arg770, and Phe771. The methyl group of $\mathbf{4 3}$ and $\mathbf{5 2}$, is involved 4 ( 2 polar/polar, 2 polar/nonpolar) and 5 ( 3 polar/polar, 5 polar/nonpolar) van der 
Waals interactions, respectively with Asn284, Leu380 and Glu382 (43) or Glu382, Arg770, and Phe771 (52).
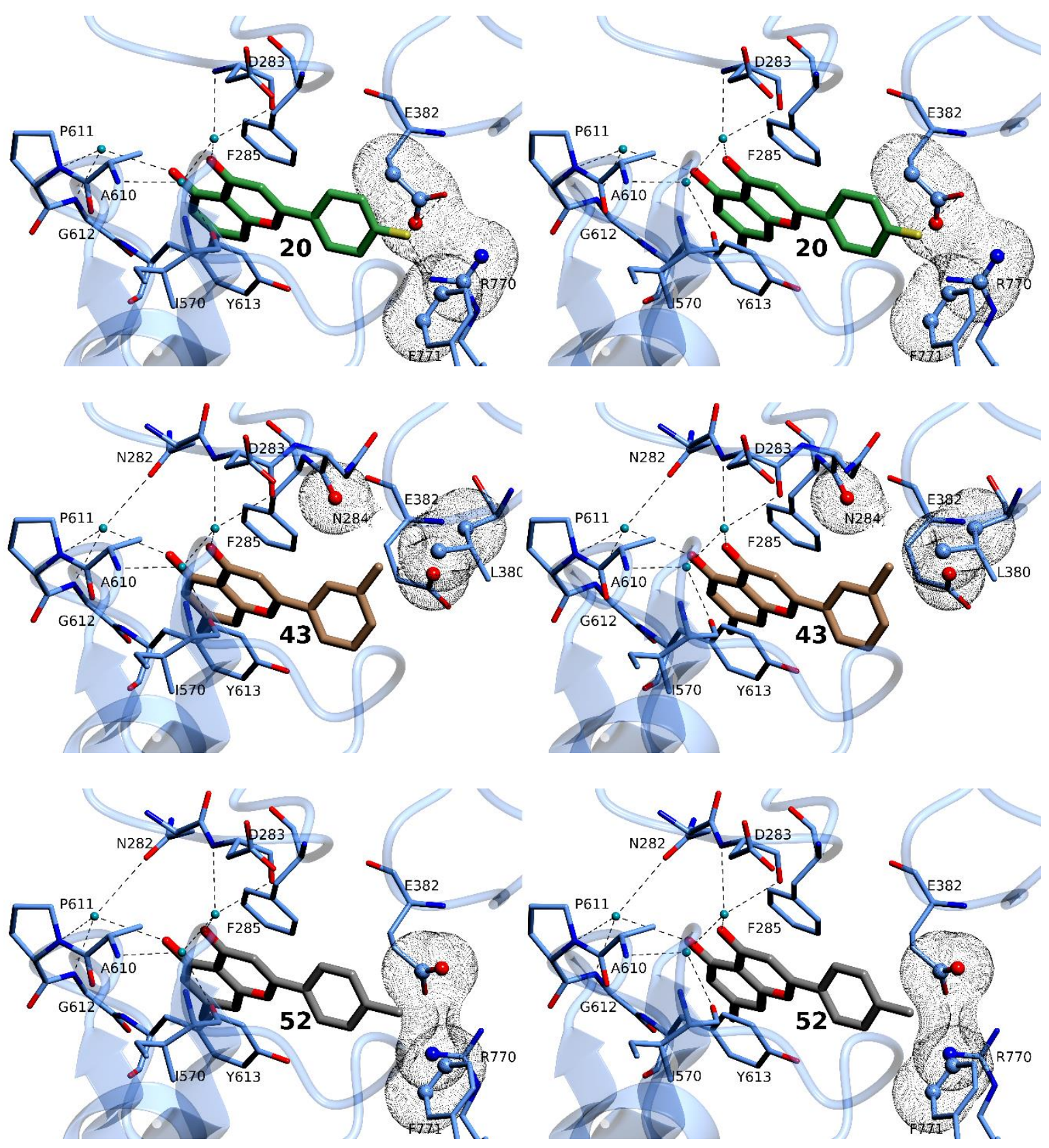

Figure 5. Stereo diagrams of the interactions of the ligands 20,43 and 52 at the inhibitor site. The inhibitor molecules are shown as thick bonds, water molecules as cyan spheres and hydrogen bonds as dashed lines and van der Waals interactions of the B ring as mesh cloud.

Comparative structural analysis of the three inhibitor complexes reveals that while $\mathbf{2 0}$ and $\mathbf{4 3}$ bind at the same location within the inhibitor binding site of rmGPb the location of $\mathbf{5 2}$ differs by approximately $0.4 \AA$, and $\mathbf{5 2}$ is more exposed to the solvent (or less buried within the protein structure). The significant difference between the inhibitory potencies of $\mathbf{2 0}$ and $\mathbf{5 2}$ (Table 1) might be attributed to the two fluorine bonds and the 12 additional van der Waals interactions 
of $\mathbf{2 0}$ with respect to the interactions of $\mathbf{5 2}$. Although, $\mathbf{2 0}$ forms two fluorine bonds and 10 van der Waals interactions in addition to those of $\mathbf{4 3}$, both inhibitors are almost equipotent $\left(K_{\mathrm{i}} \mathrm{s} 2.3\right.$ and $1.0 \mu \mathrm{M}$, respectively). The presence of the fluorine in $\mathbf{2 0}$ triggers a small but significant conformational change of Glu382 (RMSD between the two conformations is $1.1 \AA$ ). The conformation adopted by the side chain of Glu382 in the rmGPb-20 complex is very similar to the one that it adopts in the rmGPb-52 complex (RMSD between the two conformations is 0.2 $\AA$ ). Therefore, it seems that the energy cost associated with the conformational change of Glu382 that accompanies the binding of $\mathbf{2 0}$, is compensated by the additional interactions of 20, and hence 20 and $\mathbf{4 3}$ are almost equipotent.

Superposition of three inhibitor complexes onto the rmGPb - chrysin complex [16] (Fig. 6) reveals that although chrysin binds very similarly to the new inhibitors, its position differs by 0.4, 0.6, and $0.8 \AA$ from the binding locations of $\mathbf{2 0}, \mathbf{4 3}$, and $\mathbf{5 2}$, respectively. Upon binding to rmGPb, chrysin forms 96 van der Waals interactions (54 nonpolar/nonpolar, 4 polar/polar, and 38 polar/nonpolar) and two water mediated hydrogen bonds [16]. The difference in the inhibitory potency between chrysin and $\mathbf{2 0}$ might be attributed to the fluorine bonds formed by the latter compound. However, the significant difference between the inhibitory potencies of both 43 and 52 with that of chrysin cannot be attributed to the small shift in their binding location within the inhibitor site.
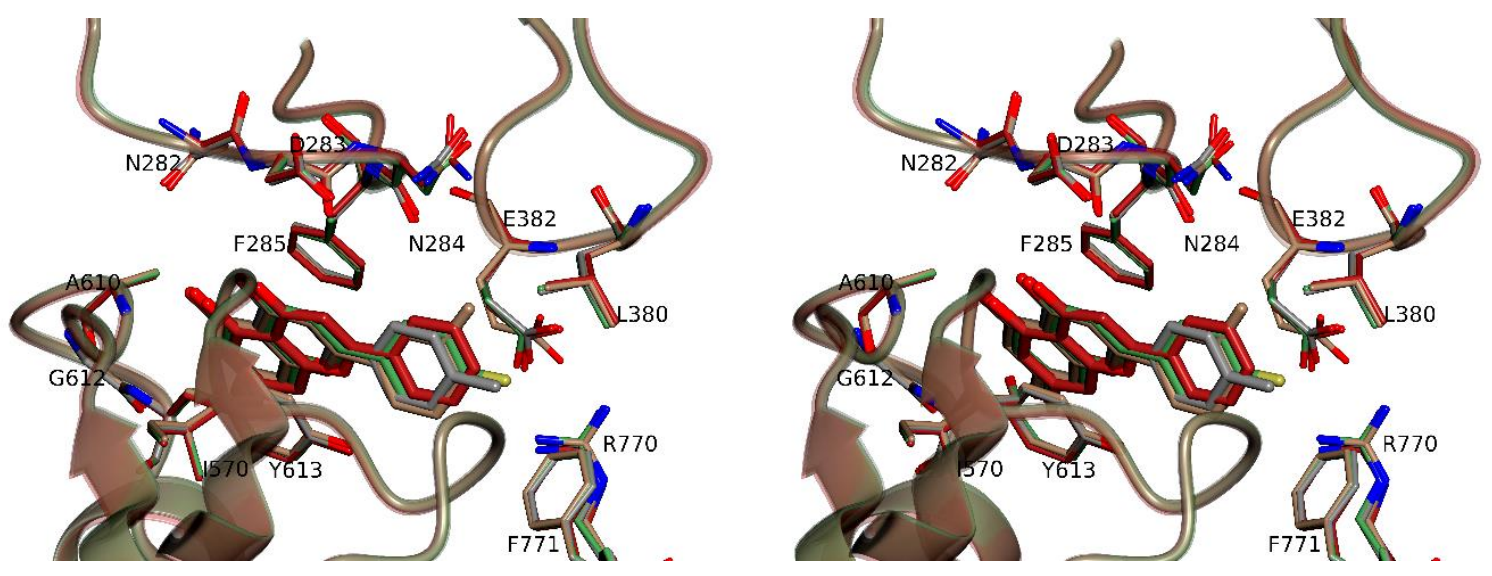

Figure 6. Stereo diagram of the superposition of the $\mathbf{2 0}, \mathbf{4 3}$, and $\mathbf{5 2}$ complexes onto the rmGPbchrysin complex [16].

\subsection{Ex-vivo Cellular Studies}


The efficacy of inhibitor $\mathbf{4 3}$ to inhibit glycogen phosphorylase was also evaluated in hepatocarcinoma HepG2 cells. For that purpose, HepG2 cells were precultured in high glucose medium (25 mM glucose), in the presence of $10 \mathrm{nM}$ insulin, to activate glycogen synthesis. Upon inhibitor 43 treatment, cells were cultured in low glucose medium ( $5 \mathrm{mM}$ glucose), in the presence of $10 \mathrm{nM}$ DEX, conditions appropriate to induce glycogenolysis. Inhibitor $\mathbf{4 3}$ was checked at a concentrations range of $55 \mu \mathrm{M}$ to $330 \mu \mathrm{M}$. Assessment of the enzymatic activity of GP in cellular extracts of HepG2 cells treated with the inhibitor $\mathbf{4 3}$ revealed high potency of inhibitor $\mathbf{4 3}$ to suppress GP activity, exhibiting $\mathrm{IC}_{50}$ of $70 \mu \mathrm{M}$ (Fig. 7).

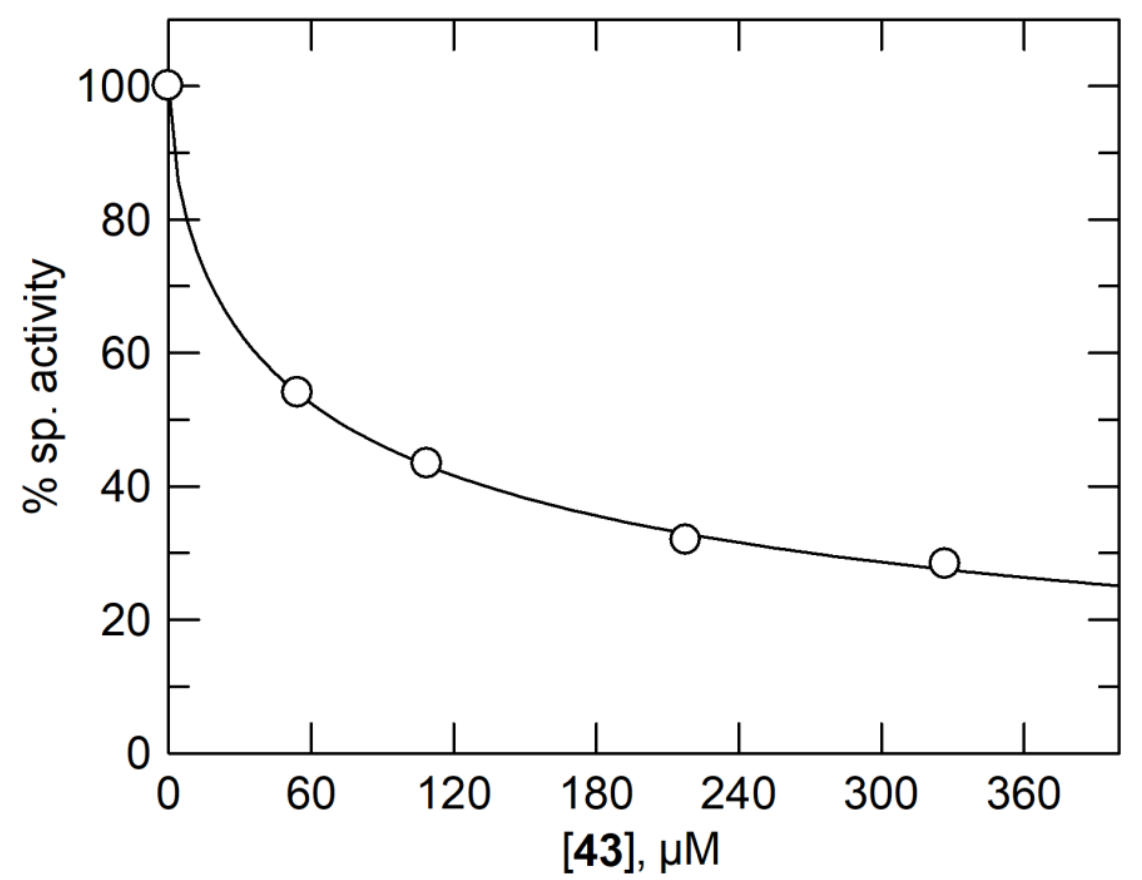

Figure 7. GP inhibition by inhibitor $\mathbf{4 3}$ in HepG2 cells. GP activity was assayed in lysates after $3 \mathrm{~h}$ incubation of the cells with 54.5, 109, 218 and $327 \mu \mathrm{M}$ of $\mathbf{4 3}$ as described in the Experimental Section. The value of $\mathrm{IC}_{50}$ was calculated as $70 \pm 2.5 \mu \mathrm{M}$ using the program GRAFIT and the "explicit weight" function to take into account all experimental error. GP activity was measured at 4 different times and determined using the same method as for the in vitro assays.

\section{Conclusions}

In silico screening for GP inhibitors acting at the inhibitor site has been performed using chrysin as the lead compound[16] and post-docking QM/MM-PBSA binding free energy calculations. By retaining the 5,7-dihydroxy-4H-chromen-4-one ligand core of chrysin and screening for different B ring substitutions exploiting the ZINC database[26], eight candidates from the in silico screening were selected for synthesis with the potential for more favourable 
interactions at the inhibitor site hydrophobic pocket. The target compounds were synthesized using a Baker-Venkataraman rearrangement-cyclization strategy, yielding the compounds in modest yields over the four step procedure. Kinetics experiments against rmGPb revealed compounds $11\left(K_{i}=1.9 \mu \mathrm{M}\right), 20\left(K_{i}=2.3 \mu \mathrm{M}\right)$ and $43\left(K_{i}=1.0 \mu \mathrm{M}\right)$ among the most potent inhibitor site compounds known to date and more potent than any previously reported natural flavonoid inhibitor; multiple inhibition studies revealed binding exclusively at the site, and this was confirmed by X-ray crystallographic studies. The crystal structure GPb - inhibitor complexes revealed the interactions responsible for the observed potencies, which included favourable halogen B ring interactions at positions 3 ' and 4', but most significantly a nonpolar substituent (particularly methyl) at the meta position. Ex-vivo experiments for the most potent inhibitor (43) were also encouraging and revealed the compound to have strong inhibitory effects on endogenous GP activity in HepG2 cells in culture $\left(\mathrm{IC}_{50}=70 \mu \mathrm{M}\right)$. In addition, optimization of the pharmacological potential of the compounds can include modification of $\mathrm{A}$ and $\mathrm{C}$ ring properties and substituents. The increased potency of flavopiridol compared to chrysin with A ring substitutions supports such an approach [16, 22]. Additionally, while natural flavonoids have quite low oral bioavailability, flavopiridol does not [44], and together with the promising cellular results obtained here for $\mathbf{4 3}$, highlights the potential of synthetic flavonoid analogues in drug discovery projects such as this.

\section{Experimental Section}

\subsection{Computational Details}

\subsubsection{Protein Preparation}

The GPb protein was prepared for calculations using the solved $1.9 \AA$ A resolution co-crystallized complex with chrysin (PDB code 3EBO) and Schrödinger's Protein Preparation Wizard [45]. The waters within $5 \AA$ of chrysin were retained, bond orders assigned and hydrogens added, with protonation states for basic and acidic residues based on $\mathrm{p} K_{\mathrm{a}}$ 's at a $\mathrm{pH}$ of 7 calculated using PROPKA[46]. Subsequent optimization of hydroxyl groups, histidine protonation states and $\mathrm{C} / \mathrm{N}$ atom flips, and side-chain $\mathrm{O} / \mathrm{N}$ atom flips of Asn and Gln residues was based on optimizing hydrogen bonding patterns. Finally, the system was softly minimised using OPLSAA (2005) forcefield with the RMSD of heavy atoms kept within $0.3 \AA$ of the crystallographic positions.

\subsubsection{Ligand Database Preparation}


Using the ZINC docking database (http://zinc.docking.org/)[26], benzoyl chloride derivatives were filtered so that the final set of screening compounds fulfilled certain criteria (MW, HBAs, HBDs) among Lipinski's 'rule of five' [47] for oral bioavailability [MW < 500 Da, hydrogen bond acceptor $(\mathrm{HBA}) \leq 10$, hydrogen bond donor $(\mathrm{HBD}) \leq 5$ and $\log \mathrm{P}<5$ ]. The formal charge of the benzoyl chlorides was set to be 0 (more suitable for synthesis) and also a limit set on the ligand flexibility for final compounds (number of rotatable bonds $\leq 5$ ) to limit entropy loss on binding; a larger number of rotatable bonds $(\geq 10)$ has also been associated with poor oral bioavailability [48]. Including these restrictions yielded 1169 benzoyl chloride derivatives. These were joined to the 5,7-dihydroxy-4H-chromen-4-one core (Figure 3) using CombiGlide 3.9 with LigPrep [27]. This protocol yielded 1239 minimised structures including potential tautomers/ionization states ready for virtual screening.

\subsubsection{Docking}

Docking of ligands was performed to the prepared protein conformation from its complex with chrysin (c.f. 4.1.1.) (model 1) and also to an induced-fit docking (IFD) GPb model (model 2) of its complex with 5,7-dihydroxy-2-(naphthalen-2-yl)-4H-chromen-4-one (B ring as a 2naphthyl). In Stage 1 of the IFD, the 5,7-dihydroxy-2-(naphthalen-2-yl)-4H-chromen-4-one was docked to the inhibitor site of model 1 using Glide 6.9 with the SP scoring function and up to 20 poses per ligand saved. The core of the ligand (A and $\mathrm{C}$ ring atoms) involved in the $\pi$ stacking was restrained to its original position (PDB code: $3 \mathrm{EBO}$ ) using core constraints (tolerance $0.10 \AA$ ). The hydrophobic pocket Leu380 sidechain was temporarily trimmed in this stage (mutated to Ala), as well as scaling of the van der Waals radii of non-polar atoms by 0.5 . Stage 2 was a Prime 4.2 refinement, with residues in the hydrophobic pocket refined. For Stage III, up to 20 protein conformations within $30 \mathrm{kcal} / \mathrm{mol}$ of the lowest-energy structure were used for Glide-SP re-docking. The top-ranked complex based on IFDscore was selected as model 2 for subsequent docking.

In the docking calculations of screening compounds to GPb models 1 and 2 with Glide 6.9[49] [50], the shape and properties of the inhibitor binding site were mapped onto grids with dimensions of $23.1 \times 23.1 \times 23.1 \AA$ centred on the bound ligands. Standard parameters were applied including van der Waals scaling for non-polar atoms (by 0.8) to include modest 'induced-fit' effects. Core constraints (RMSD of $0.10 \AA$ ) were applied on the A and C ring atoms. Docking calculations were performed using both Glide-SP and -XP, both of which included post-docking minimization with strain correction. All 1169 ligands were docked with 
1 pose per ligand saved for each docking calculation, and compounds ranked by GlideScore. For each GP model (models 1 and 2), ligands were re-ranked by consensus scoring using a Simple Sum Rank [28] of the Glide-SP and -XP ranks. RMSDs between ligand atom positions for compounds that gave both SP and XP results were calculated to determine if similar (consensus) poses for were obtained [30]. A RMSD cut-off $<1.0 \AA$ was applied for consensus pose agreement and retention of ligands. Additionally, ligands not feasible with the BakerVenkataraman rearrangement and/or with B ring substituents considered too bulky were filtered. Based on this process, the top 200 ligands for each of the two $\mathrm{GPb}$ conformation models 1 and 2 proceeded to the QM/MM-PBSA binding free energy calculations.

\subsubsection{QM/MM-PBSA Calculations}

Glide-SP poses for the top 200 ligands from each GPb model for docking were used directly as input for QM/MM-PBSA calculations. Binding free energies were calculated as the difference in energies between the bound and the unbound states of the protein-ligand complexes using Eq. (1).

$$
\Delta G_{\text {bind }}=\Delta E_{Q M / M M}+\Delta G_{\text {solv }}-T \Delta S_{M M} \quad \text { Eq. (1) }
$$

$E_{Q M / M M}$ and $S_{M M}$ represent the total molecular mechanics energy (internal, electrostatic and van der Waals) and an entropy estimate, respectively; $G_{\text {solv }}$, the solvation free energy. DFT with the M06-2X functional[51] and the LACVP*+ basis set $[52,53]$ was used for the QM region (ligand, Phe 285 and Tyr 613 sidechains) and the rest of the protein was described using MM with the OPLS-AA(2005) forcefield [54]. Effectively, the MM region polarizes the QM region, with electrostatic effects between the MM point charges and the QM wavefunction, and the van der Waals interactions between QM and MM atoms accounted for.[54] No cut-off for non-bond interactions was employed. Corrections for basis set superposition error (BSSE) were not included given that the key QM interaction region atoms were the same for all ligands (rings A and C with Phe285 and Tyr613) and resulting cancellation of errors [16]. Additionally, while the magnitude of BSSE is dependent on intermolecular distance [55], the core constraints employed in the docking phase counteracted this effect. Bulk solvation effects were included using Poisson-Boltzmann Surface Area (PBSA) [56], with the default solute (internal) dielectric constant of 1.0 employed. The $\Delta G_{\text {solv }}$ term was calculated as two components:

$$
\Delta G_{\text {solv }}=\Delta G_{P B}^{\text {solv }}+\Delta G_{S A}^{\text {solv }} \quad \text { Eq. (2) }
$$


where $\Delta G_{P B}^{\text {Solv }}$ and $\Delta G_{S A}^{\text {solv }}$ account for the polar and non-polar (proportional to changes in solvent accessible surface areas) contributions, as described previously [34]. Meanwhile, an estimate for the loss of ligand entropy $\left(\Delta S_{M M}\right)$ on binding was calculated using MM with the OPLS-AA(2005) forcefield [54] and the Rigid Rotor Harmonic Oscillator (RRHO) approximation. Using this method, the change in vibrational, rotational and translational entropy of the ligands on binding was considered. QM/MM-PBSA calculations were performed using QSite 6.9 [49]; RRHO calculations using MacroModel 11.0 [49].

The $\Delta G_{\text {bind }}$ values of ligands from both protein models (model 1 and 2) were compared and the best $\Delta G_{\text {bind }}$ value taken, together with its receptor-ligand complex. Ligands were ranked by $\Delta G_{\text {bind }}$ values and those with a value $<-11 \mathrm{kcal} / \mathrm{mol}$ considered further. A Prime 4.2 [49] minimization was used to refine the corresponding protein-ligand complexes using default settings that included the OPLS3 forcefield [57] and VSGB solvation model [58]. Sidechains of residues surrounding the hydrophobic pocket (Asp283, Asn284, Glu382, Leu380, His571, Glu572, Tyr573, Arg770 and Phe771) together with the ligands were refined during this process, but flavonoid rings $\mathrm{A}$ and $\mathrm{C}$ constrained to maintain the orginal $\pi$-stacking distances with Phe285 and Tyr613. Final QM/MM-PBSA binding free energies were determined using the Prime output complexes as input, employing the same settings as before.

\section{2 - Synthetic Methods}

\section{General procedure for the synthesis of $1,9,10,11,20,43$ and 52}

2'-Hydroxy-4',6'-dimethoxyacetophenone (1 eq.) was added to the required benzoyl chloride (1.1 eq.) dissolved in dichloromethane $(0.1 \mathrm{M})$. 4-Dimethylaminopyridine $(0.1$ eq.) and triethylamine (1.5 eq.) were added and the reaction was allowed to stir for 24 hours under a nitrogen atmosphere. Upon completion (TLC - EtOAc, petroleum ether mixtures) the product was acidified with $\mathrm{HCl}$ and the organic layer was washed with distilled water, brine and dried $\left(\mathrm{MgSO}_{4}\right)$. The solution was evaporated in vacuo leaving a crude solid. The crude solid was dissolved in dry THF $(0.1 \mathrm{M})$ and $\mathrm{NaH}$ (60\% in mineral oil, 1.0 eq.) was added and the reaction was heated at reflux for 20 hours. Upon completion (TLC - EtOAc, petroleum ether mixtures) the solution was washed with $\mathrm{HCl}$ and extracted with EtOAc. The organic layer was washed with distilled water, brine and dried $\left(\mathrm{MgSO}_{4}\right)$. The solution was evaporated in vacuo leaving a crude solid. The crude solid was suspended in conc. $\mathrm{H}_{2} \mathrm{SO}_{4}$ and acetic acid and this mixture was allowed to stir at reflux for 15 hours. After allowing to cool, the solution was poured onto an ice/water slurry and the resulting crystalline solid was collected using vacuum filtration. 
The crude solid was suspended in $\mathrm{HBr}$ (47-49\%) and glacial acetic acid and this mixture heated at reflux for 40 hours. After allowing to cool, the solution was poured onto an ice/water slurry, and following isolation and purification by flash column chromatography, yielded the title compound as a pure solid.

\section{Procedure for the synthesis of 2}

2,4,6-Trimethoxybenzoic acid (1.1 g, 5.2mmol) was dissolved in dichloromethane (65 $\mathrm{mL})$, the reaction flask was purged with nitrogen for 10 minutes and then oxalyl chloride $(0.50 \mathrm{~mL}$, $5.7 \mathrm{mmol}$ ) was added along with 2 drops of dimethylformamide. The mixture was allowed to react and the progress was monitored by TLC (50\% EtOAc in petroleum ether) over the period of an hour until complete. The solvent was removed in vacuo to yield a viscous yellow oil (1.4 $\mathrm{g}, 6 \mathrm{mmol})$. The crude product was dissolved in dichloromethane $(50 \mathrm{~mL})$ and 2'hydroxyacetophenone $(0.66 \mathrm{~mL}, 5.5 \mathrm{mmol})$ was added along with triethylamine $(1.1 \mathrm{~mL})$ and 4-dimethylaminopyridine $(70 \mathrm{mg}$ ) and the reaction was allowed to progress overnight at room temperature. The organic layer was washed with $\mathrm{NaOH}(2 \times 25 \mathrm{~mL})$, water $(2 \times 25 \mathrm{~mL})$ and brine $(30 \mathrm{~mL})$, and the solvent was removed in vacuo to yield a viscous yellow oil (1.8 $\mathrm{g}, 5.4$ mmol). The flask containing the crude material was purged with nitrogen for ten minutes followed by the addition of anhydrous tetrahydrofuran $(50 \mathrm{~mL})$, followed by $\mathrm{NaH}(60 \%$ in mineral oil, $0.22 \mathrm{~g}, 5.4 \mathrm{mmol}$ ) and the reaction heated at $66{ }^{\circ} \mathrm{C}$ for 20 hours. The solution was acidified with $\mathrm{HCl}(250 \mathrm{~mL})$ to yield a pale yellow crystalline precipitate by vacuum filtration (1.12 g, $3.4 \mathrm{mmol})$. Flash column chromatography $\left(\mathrm{SiO}_{2}\right.$; ethyl acetate:petroleum ether) yielded the desired rearranged product $(0.8 \mathrm{~g}, 2.5 \mathrm{mmol}) . \mathrm{H}_{2} \mathrm{SO}_{4}(5 \mathrm{~mL})$ was added along with $\mathrm{CH}_{3} \mathrm{COOH}(60 \mathrm{~mL})$ and this was heated to reflux for 6 hours until completion, as determined by TLC. The solution was poured over an ice/water slurry to yield cream-like crystals $(0.2 \mathrm{~g}$ $0.64 \mathrm{mmol})$. Hydroiodic acid $(5 \mathrm{~mL})$ was added to these crystals along with phenol $(3.21 \mathrm{~g})$ and this mixture was heated to $120{ }^{\circ} \mathrm{C}$ (bath temperature) for 2 hours. The solution was then poured over an ice/water slurry $(300 \mathrm{~mL})$ to yield a pale-cream crystalline solid $(20 \mathrm{mg}, 0.07$ mmol).

\section{3 - Kinetics Measurement}

$\mathrm{rmGPb}$ was purified from rabbit skeletal muscles following the protocol developed by Fischer and Krebs [59], while hlGPb was produced as described previously [60]. rmGPa and 
hlGPa were prepared by phosphorylation of $\mathrm{rmGPb}$ and hlGPb, respectively, using a truncated form of the $\gamma$ (catalytic) subunit of rabbit skeletal muscle phosphorylase kinase [61]. Kinetic studies were performed at $30{ }^{\circ} \mathrm{C}$ in the direction of glycogen synthesis using the method by Saheki et al. [62] for the determination of the released orthophosphate anions. $3 \mu \mathrm{g} / \mathrm{mL} \mathrm{rmGPb}$, rmGPa, or $1 \mu \mathrm{g} / \mathrm{mL} \mathrm{hlGPa}$ were assayed following an established protocol described previously [63] and various concentrations of inhibitors. All inhibitors were treated as allosteric inhibitors (do not obey Michaelis-Menten model) and hence Hill plots were produced (Figures S1-S3). Inhibition constant $\left(K_{\mathrm{i}}\right)$ values were then calculated from the intercept to horizontal axis of the plot of $K_{\mathrm{M}(\text { app.) }}$ vs [inhibitor] using the non-linear regression program GRAFIT [64].

\section{4 - X-ray Crystallography}

rmGPb crystals were grown by the batch method as described previously [63]. X-ray crystallographic binding studies were performed by diffusion of $20(10 \mathrm{mM} ; 38 \mathrm{~h}), \mathbf{4 3}(10 \mathrm{mM}$; $24 \mathrm{~h})$, and $\mathbf{5 2}(10 \mathrm{mM} ; 47 \mathrm{~h})$ solution in the crystallization media supplemented with $25 \%(\mathrm{v} / \mathrm{v})$ DMSO in preformed $\mathrm{rmGPb}$ crystals at room temperature prior to data collection. X-ray diffraction data were collected using a $\mathrm{Cu}$ X-ray microfocus source (Oxford Diffraction SuperNova) equipped with a 4-kappa goniometer and the ATLAS CCD (135 mm) detector at room temperature. X-ray data processing was performed by the program CrysalisPro (Agilent Technologies UK Ltd.) [65]. Scaling and merging of intensities were performed by Aimless and the optimum resolution was selected based on the $C C^{1 / 2}$ criterion [66]. Crystallographic refinement of the complexes was performed by maximum-likelihood methods using REFMAC [67]. The starting model employed for the refinement of the complexes was the structure of $\mathrm{T}$ state rmGPb in complex with a $C$ - $\beta$-D-glucopyranosyl triazole inhibitor after the removal of the ligand [68]. Ligand molecule coordinates and topologies were constructed using AceDRG [69] within Coot [70] and they were fitted to the electron density maps after adjustment of their torsion angles. A summary of the data processing and refinement statistics for the inhibitor complex structures is given in Table 3 . The validity of the refinement procedure was checked using the PDB_REDO server [71]. As there were more than five reflections per atom available, both an isotropic and an anisotropic B-factor model were considered, and the isotropic B-factor model was selected based on the Hamilton R ratio test. A TLS model for grouped atom movement with one TLS group was used. The stereochemistry of the protein residues was validated by MolProbity [72]. Accessibility surfaces were calculated by the NACCESS program [73]. Figures were prepared with the CCP4 Molecular Graphics program [74]. The 
coordinates of the new structures have been deposited with the RCSB Protein Data Bank [75] with codes presented in Table 3.

Table 3. Summary of the diffraction data processing and refinement statistics for the rmGPb complexes. Values in parentheses are for the outermost shell.

\begin{tabular}{|c|c|c|c|}
\hline rmGPb complex & 20 & 43 & 52 \\
\hline \multicolumn{4}{|c|}{ Data collection and processing statistics } \\
\hline Resolution $(\AA)$ & $13.74-2.33$ & $13.67-2.38$ & $13.68-2.40$ \\
\hline Outermost shell $(\AA)$ & $2.42-2.33$ & $2.47-2.38$ & $2.49-2.40$ \\
\hline Reflections measured & 175524 & 200647 & 164680 \\
\hline Unique reflections & 38529 (3446) & 34581 (3009) & $34314(3151)$ \\
\hline Multiplicity & $4.6(3.1)$ & $5.8(4.3)$ & $4.8(3.4)$ \\
\hline$R_{\text {merge }}$ & $0.085(0.596)$ & $0.095(0.570)$ & $0.101(0.623)$ \\
\hline Completeness (\%) & $92.6(80.3)$ & $90.1(75.7)$ & $91.2(80.2)$ \\
\hline$<\mathrm{I} / \sigma \mathrm{I}>$ & $10.7(1.7)$ & $11.3(1.9)$ & $10.7(1.4)$ \\
\hline$C C^{1 / 2}$ & $0.991(0.768)$ & $0.995(0.840)$ & $0.988(0.754)$ \\
\hline
\end{tabular}

Refinement statistics

\begin{tabular}{|l|c|c|c|}
\hline$R_{\text {cryst }}$ & $0.164(0.256)$ & $0.157(0.238)$ & $0.168(0.264)$ \\
\hline$R_{\text {free }}$ & $0.212(0.294)$ & $0.211(0.244)$ & $0.211(0.301)$ \\
\hline No of solvent molecules & 241 & 227 & 244 \\
\hline
\end{tabular}

r.m.s. deviation from ideality in

\begin{tabular}{|l|c|c|c|}
\hline bonds $(\AA)$ & 0.005 & 0.004 & 0.003 \\
\hline angles $\left({ }^{\circ}\right)$ & 1.3 & 1.2 & 0.9 \\
\hline Average B factor $\left(\AA^{2}\right)$ & 28.8 & 31.5 & 27.1 \\
\hline Protein atoms & 29.1 & 29.2 & 24.2 \\
\hline Solvent molecules & 49.7 & 41.4 & 50.7 \\
\hline Inhibitor atoms & $6 Y 50$ & $6 Y 55$ & $6 Y 5 C$ \\
\hline PDB entry & & 6
\end{tabular}

\section{5 - Ex-vivo Experiments}

Assessment of the efficacy of the potent GP inhibitors to suppress endogenous GP activity in hepatocarcinoma HepG2 cells was performed as previously described [76]. Briefly, human HepG2 hepatocarcinoma cells were maintained in Dulbecco's modified Eagle medium 
(DMEM), containing $25 \mathrm{mM}$ glucose 10\% FBS, $2 \mathrm{mM}$ glutamine, and penicillin/streptomycin, in a humidified atmosphere with $5 \% \mathrm{CO} 2$, at $37{ }^{\circ} \mathrm{C}$. For GP activity assessment, cells were seeded in $60 \mathrm{~mm}$ culture dishes at a density of $1.5 \times 10^{6}$ cells per dish. After cell attachment (16-18 $\mathrm{h}$ ), the medium was replaced by serum-free medium containing $10 \mathrm{nM}$ dexamethasone, $25 \mathrm{mM}$ glucose, and $10 \mathrm{nM}$ insulin, and cells were further incubated for $16-18 \mathrm{~h}$ to replete glycogen stores. Cells were then incubated in the absence and presence of $\mathbf{4 3}$ at a concentration range of 54.5 to $327 \mu \mathrm{M}$, in serum-free medium supplemented with $5 \mathrm{mM}$ glucose and $10 \mathrm{nM}$ dexamethasone (low-glucose growth medium) for $3 \mathrm{~h}$. Subsequently, cells were washed in phosphate buffer, harvested, centrifuged at $700 \mathrm{X} \mathrm{g}$ for $5 \mathrm{~min}$. Cell pellets were resuspended in $20 \mathrm{mM}$ Tris $\mathrm{pH} 7.5$, containing $0.05 \%$ Triton and supplemented with $1 \mathrm{mM}$ PMSF. Then, cell lysates were sonicated followed by centrifugation at $12,000 \mathrm{X}$ g at $4^{0} \mathrm{C}$ for $15 \mathrm{~min}$. GP activity was assessed in cleared lysates as described above. Glycogen (1\% w/v) and 20mM Glc-1-P were added to the lysates for the assay while GP activity values were normalized against total protein amount, for each condition. The $\mathrm{IC}_{50}$ value of inhibitor $\mathbf{4 3}$ was calculated by the $\%$ GP activity vs inhibitor concentration diagram using the nonlinear regression program GRAFIT [64].

\section{Acknowledgments}

We would like to thank Dr S.E. Zographos and Ms P.G.V. Liggri for their help during X-ray data collection. We acknowledge support of this work by the project "The National Research Infrastructures on integrated biology, drug screening efforts and drug target functional characterization - INSPIRED-Thessaly" (MIS 5002550) which is implemented under the Action "Reinforcement of the Research and Innovation Infrastructure", funded by the Operational Programme "Competitiveness, Entrepreneurship and Innovation" (NSRF 20142020) and co-financed by Greece and the European Union (European Regional Development Fund). E.K. would like to acknowledge financial support by Greece and the European Union 
(European Social Fund- ESF) through the Operational Programme «Human Resources

Development, Education and Lifelong Learning» in the context of the project "Strengthening Human Resources Research Potential via Doctorate Research” (MIS-5000432), implemented by the State Scholarships Foundation (IKY). The work was also supported in part by the General Secretariat for Research and Technology and the Hellenic Foundation for Research and Innovation (HFRI) under the HFRI PhD fellowship grant to A.G.K. (code: 2246).

\section{Supporting Information}

Supplementary data related to this article can be found at XXXX and includes Figures from multiple inhibition studies (Dixon plots); melting point, ${ }^{1} \mathrm{H}-\mathrm{NMR}$ and ${ }^{13} \mathrm{C}-\mathrm{NMR}$, IR and MS characterisation data (purities $>95 \%$ ) for identified potent inhibitors $(\mathbf{9}, \mathbf{1 1}, \mathbf{2 0}, \mathbf{4 3}$ and 52); copies of ${ }^{1} \mathrm{H}-\mathrm{NMR}$ spectra and HPLC chromatograms.

\section{References}

[1] World Health Organisation. www.who.int (15/05/20).

[2] R.A. DeFronzo, R.C. Bonadonna, E. Ferrannini, Pathogenesis of NIDDM. A balanced overview, Diabetes Care, 15 (1992) 318-368.

[3] M. Roden, E. Bernroider, Hepatic glucose metabolism in humans - its role in health and disease, Best Practice \& Research Clinical Endocrinology \& Metabolism, 17 (2003) 365-383. [4] N.G. Oikonomakos, Glycogen phosphorylase as a molecular target for type 2 diabetes therapy, Curr. Protein. Pept. Sci., 3 (2002) 561-586.

[5] C.E. Zois, A.L. Harris, Glycogen metabolism has a key role in the cancer microenvironment and provides new targets for cancer therapy, J. Molec. Med.-JMM, 94 (2016) 137-154.

[6] L. Xu, H. Sun, Pharmacological manipulation of brain glycogenolysis as a therapeutic approach to cerebral ischemia, Mini Rev. Med. Chem., 10 (2010) 1188-1193.

[7] T. Guan, Y.S. Qian, X.Z. Tang, M.H. Huang, L.F. Huang, Y.M. Li, H.B. Sun, Maslinic Acid, a Natural Inhibitor of Glycogen Phosphorylase, Reduces Cerebral Ischemic Injury in Hyperglycemic Rats by GLT-1 Up-Regulation, J. Neurosci. Res., 89 (2011) 1829-1839.

[8] L. Somsák, K. Czifrák, M. Tóth, É. Bokor, E.D. Chrysina, K.M. Alexacou, J.M. Hayes, C. Tiraidis, E. Lazoura, D.D. Leonidas, S.E. Zographos, N.G. Oikonomakos, New inhibitors of glycogen phosphorylase as potential antidiabetic agents, Curr. Med. Chem., 15 (2008) 29332983.

[9] A.L. Kantsadi, A. Apostolou, S. Theofanous, G.A. Stravodimos, E. Kyriakis, V.A. Gorgogietas, D.S. Chatzileontiadou, K. Pegiou, V.T. Skamnaki, D. Stagos, D. Kouretas, A.M. Psarra, S.A. Haroutounian, D.D. Leonidas, Biochemical and biological assessment of the inhibitory potency of extracts from vinification byproducts of Vitis vinifera extracts against glycogen phosphorylase, Food Chem. Toxicol., 67 (2014) 35-43. 
[10] E.D. Chrysina, M.N. Kosmopoulou, C. Tiraidis, R. Kardakaris, N. Bischler, D.D. Leonidas, Z. Hadady, L. Somsak, T. Docsa, P. Gergely, N.G. Oikonomakos, Kinetic and crystallographic studies on 2-(beta-D-glucopyranosyl)-5-methyl-1, 3, 4-oxadiazole, benzothiazole, and -benzimidazole, inhibitors of muscle glycogen phosphorylase b. Evidence for a new binding site, Protein Sci., 14 (2005) 873-888.

[11] G.A. Stravodimos, B.A. Chetter, E. Kyriakis, A.L. Kantsadi, D.S. Chatzileontiadou, V.T. Skamnaki, A. Kato, J.M. Hayes, D.D. Leonidas, Phytogenic Polyphenols as Glycogen Phosphorylase Inhibitors: The Potential of Triterpenes and Flavonoids for Glycaemic Control in Type 2 Diabetes, Curr. Med. Chem., 24 (2017) 384-403.

[12] J.M. Hayes, A.L. Kantsadi, D.D. Leonidas, Natural products and their derivatives as inhibitors of glycogen phosphorylase: potential treatment for type 2 diabetes, Phytochem. Rev., 13 (2014) 471-498.

[13] S. Jakobs, D. Fridrich, S. Hofem, G. Pahlke, G. Eisenbrand, Natural flavonoids are potent inhibitors of glycogen phosphorylase, Mol. Nutr. Food Res., 50 (2006) 52-57.

[14] A. Kato, N. Nasu, K. Takebayashi, I. Adachi, Y. Minami, F. Sanae, N. Asano, A.A. Watson, R.J. Nash, Structure-activity relationships of flavonoids as potential inhibitors of glycogen phosphorylase, J. Agric. Food. Chem., 56 (2008) 4469-4473.

[15] O. Kamiyama, F. Sanae, K. Ikeda, Y. Higashi, Y. Minami, N. Asano, I. Adachi, A. Kato, In vitro inhibition of alpha-glucosidases and glycogen phosphorylase by catechin gallates in green tea, Food Chem., 122 (2010) 1061-1066.

[16] K.E. Tsitsanou, J.M. Hayes, M. Keramioti, M. Mamais, N.G. Oikonomakos, A. Kato, D.D. Leonidas, S.E. Zographos, Sourcing the affinity of flavonoids for the glycogen phosphorylase inhibitor site via crystallography, kinetics and QM/MM-PBSA binding studies: Comparison of chrysin and flavopiridol, Food Chem. Toxicol., 61 (2013) 14-27.

[17] L. Anila, N.R. Vijayalakshmi, Beneficial effects of flavonoids from Sesamum indicum, Emblica officinalis and Momordica charantia, Phytother. Res., 14 (2000) 592-595.

[18] M. Ahmad, M.S. Akhtar, T. Malik, A.H. Gilani, Hypoglycaemic action of the flavonoid fraction of Cuminum nigrum seeds, Phytother. Res., 14 (2000) 103-106.

[19] K.C. Ong, H.E. Khoo, Effects of myricetin on glycemia and glycogen metabolism in diabetic rats, Life Sci., 67 (2000) 1695-1705.

[20] O. Kamiyama, F. Sanae, K. Ikeda, Y. Higashi, Y. Minami, N. Asano, I. Adachi, A. Kato, In vitro inhibition of $\alpha$-glucosidases and glycogen phosphorylase by catechin gallates in green tea, Food Chem., 122 (2010) 1061-1066.

[21] N.G. Oikonomakos, J.B. Schnier, S.E. Zographos, V.T. Skamnaki, K.E. Tsitsanou, L.N. Johnson, Flavopiridol inhibits glycogen phosphorylase by binding at the inhibitor site, J. Biol. Chem., 275 (2000) 34566-34573.

[22] L.J. Hampson, C. Arden, L. Agius, M. Ganotidis, M.N. Kosmopoulou, C. Tiraidis, Y. Elemes, C. Sakarellos, D.D. Leonidas, N.G. Oikonomakos, Bioactivity of glycogen phosphorylase inhibitors that bind to the purine nucleoside site, Bioorg. Med. Chem., 14 (2006) 7835-7845.

[23] N.B. Madsen, S. Shechosky, R.J. Fletterick, Site-Site Interactions in Glycogen Phosphorylase-B Probed by Ligands Specific for Each Site, Biochem., 22 (1983) 4460-4465.

[24] P.J. Kasvinsky, N.B. Madsen, J. Sygusch, R.J. Fletterick, Regulation of Glycogen Phosphorylase-a by Nucleotide Derivatives - Kinetic and X-Ray Crystallographic Studies, J. Biol. Chem., 253 (1978) 3343-3351.

[25] N.G. Oikonomakos, L. Somsak, Advances in glycogen phosphorylase inhibitor design, Curr. Opin. Invest. Drugs, 9 (2008) 379-395.

[26] J.J. Irwin, T. Sterling, M.M. Mysinger, E.S. Bolstad, R.G. Coleman, ZINC: A Free Tool to Discover Chemistry for Biology, J. Chem. Inf. Model., 52 (2012). 1757-1768.

[27] Schrödinger, LLC, New York, NY, 2018. 
[28] M. Feher, Consensus scoring for protein-ligand interactions, Drug Discov. Today, 11 (2006) 421-428.

[29] V. Parmenopoulou, A.L. Kantsadi, V.G. Tsirkone, D.S.M. Chatzileontiadou, S. Manta, S.E. Zographos, C. Molfeta, G. Archontis, L. Agius, J.M. Hayes, D.D. Leonidas, D. Komiotis, Structure based inhibitor design targeting glycogen phosphorylase b. Virtual screening, synthesis, biochemical and biological assessment of novel N-acyl-beta-Dglucopyranosylamines, Biorg. Med. Chem., 22 (2014) 4810-4825.

[30] D.R. Houston, M.D. Walkinshaw, Consensus Docking: Improving the Reliability of Docking in a Virtual Screening Context, J. Chem. Inf. Model., 53 (2013) 384-390.

[31] J.M. Hayes, G. Archontis, MM-GB(PB)SA Calculations of Protein-Ligand Binding Free Energies, in: L. Wang (Ed.) Molecular Dynamics: Studies of Synthetic and Biological Macromolecules, Published Intech Open, 2012.

[32] K. Wichapong, A. Rohe, C. Platzer, I. Slynko, F. Erdmann, M. Schmidt, W. Sippl, Application of Docking and QM/MM-GBSA Rescoring to Screen for Novel Myt1 Kinase Inhibitors, J. Chem. Inf. Model., 54 (2014) 881-893.

[33] P.C. Su, C.C. Tsai, S. Mehboob, K.E. Hevener, M.E. Johnson, Comparison of radii sets, entropy, QM methods, and sampling on MM-PBSA, MM-GBSA, and QM/MM-GBSA ligand binding energies of F-tularensis enoyl-ACP reductase (FabI), J. Comput. Chem., 36 (2015) 1859-1873.

[34] S. Manta, A. Xipnitou, C. Kiritsis, A.L. Kantsadi, J.M. Hayes, V.T. Skamnaki, C. Lamprakis, M. Kontou, P. Zoumpoulakis, S.E. Zographos, D.D. Leonidas, D. Komiotis, 3'Axial $\mathrm{CH}_{2} \mathrm{OH}$ Substitution on Glucopyranose does not Increase Glycogen Phosphorylase Inhibitory Potency. QM/MM-PBSA Calculations Suggest Why, Chem. Biol. Drug Des., 79 (2012) 663-673.

[35] J. Begum, V.T. Skamnaki, C. Moffatt, N. Bischler, J. Sarrou, A.L. Skaltsounis, D.D. Leonidas, N.G. Oikonomakos, J.M. Hayes, An evaluation of indirubin analogues as phosphorylase kinase inhibitors, J. Mol. Graph Model., 61 (2015) 231-242.

[36] E.P. Gillis, K.J. Eastman, M.D. Hill, D.J. Donnelly, N.A. Meanwell, Applications of Fluorine in Medicinal Chemistry, J. Med. Chem., 58 (2015) 8315-8359.

[37] Y.J. Fang, W.W. Cao, M.M. Xia, S.Y. Pan, X.Y. Xu, Study of Structure and Permeability Relationship of Flavonoids in Caco-2 Cells, Nutrients, 9 (2017).

[38] J.B. Baell, G.A. Holloway, New Substructure Filters for Removal of Pan Assay Interference Compounds (PAINS) from Screening Libraries and for Their Exclusion in Bioassays, J. Med. Chem., 53 (2010) 2719-2740.

[39] I.H. Segel, Enzyme Kinetics, Wiley Interscience, New York, 1993.

[40] N.B. Madsen, S. Shechosky, R.J. Fletterick, Site-site interactions in glycogen phosphorylase b probed by ligands specific for each site, Biochemistry, 22 (1983) 4460-4465.

[41] E. Kyriakis, G.A. Stravodimos, A.L. Kantsadi, D.S. Chatzileontiadou, V.T. Skamnaki, D.D. Leonidas, Natural flavonoids as antidiabetic agents. The binding of gallic and ellagic acids to glycogen phosphorylase b, FEBS Lett., 589 (2015) 1787-1794.

[42] D. Liebschner, P.V. Afonine, N.W. Moriarty, B.K. Poon, O.V. Sobolev, T.C. Terwilliger, P.D. Adams, Polder maps: improving OMIT maps by excluding bulk solvent, Acta Crystallogr D Struct. Biol., 73 (2017) 148-157.

[43] G. Cavallo, P. Metrangolo, R. Milani, T. Pilati, A. Priimagi, G. Resnati, G. Terraneo, The Halogen Bond, Chem. Rev., 116 (2016) 2478-2601.

[44] B.J. Xia, X. Liu, Q. Zhou, Q. Feng, Y. Li, W. Liu, Z.Q. Liu, Disposition of orally administered a promising chemotherapeutic agent flavopiridol in the intestine, Drug Dev. Ind. Pharm., 39 (2013) 845-853.

[45] E. Harder, W. Damm, J. Maple, C. Wu, M. Reboul, J.Y. Xiang, L. Wang, D. Lupyan, M.K. Dahlgren, J.L. Knight, J.W. Kaus, D.S. Cerutti, G. Krilov, W.L. Jorgensen, R. Abel, R.A. 
Friesner, OPLS3: A force field providing broad coverage of drug-like small molecules and proteins, J. Chem. Theory Comput., 12 (2016) 281-296.

[46] C.R. Sondergaard, M.H.M. Olsson, M. Rostkowski, J.H. Jensen, Improved Treatment of Ligands and Coupling Effects in Empirical Calculation and Rationalization of pK(a) Values, J. Chem. Theory Comput., 7 (2011) 2284-2295.

[47] C.A. Lipinski, F. Lombardo, B.W. Dominy, P.J. Feeney, Experimental and computational approaches to estimate solubility and permeability in drug discovery and development settings, Adv. Drug Del. Rev., 46 (2001) 3-26.

[48] D.F. Veber, S.R. Johnson, H.Y. Cheng, B.R. Smith, K.W. Ward, K.D. Kopple, Molecular properties that influence the oral bioavailability of drug candidates, J. Med. Chem., 45 (2002) 2615-2623.

[49] L.L.C. Schrodinger, Modeling Software Suite, in, New York, 2015.

[50] R.A. Friesner, J.L. Banks, R.B. Murphy, T.A. Halgren, J.J. Klicic, D.T. Mainz, M.P. Repasky, E.H. Knoll, M. Shelley, J.K. Perry, D.E. Shaw, P. Francis, P.S. Shenkin, Glide: a new approach for rapid, accurate docking and scoring. 1. Method and assessment of docking accuracy, J. Med. Chem., 47 (2004) 1739-1749.

[51] Y. Zhao, D.G. Truhlar, The M06 suite of density functionals for main group thermochemistry, thermochemical kinetics, noncovalent interactions, excited states, and transition elements: two new functionals and systematic testing of four M06-class functionals and 12 other functionals, Theor. Chem. Acc., 120 (2008) 215-241.

[52] P.J. Hay, W.R. Wadt, Abinitio Effective Core Potentials for Molecular Calculations Potentials for K to Au Including the Outermost Core Orbitals, J. Chem. Phys., 82 (1985) 299310.

[53] W.J. Hehre, R. Ditchfield, J.A. Pople, Self-Consistent Molecular-Orbital Methods .12. Further Extensions of Gaussian-Type Basis Sets for Use in Molecular-Orbital Studies of Organic-Molecules, J. Chem. Phys., 56 (1972) 2257-2261.

[54] G.A. Kaminski, R.A. Friesner, J. Tirado-Rives, W.L. Jorgensen, Evaluation and reparametrization of the OPLS-AA force field for proteins via comparison with accurate quantum chemical calculations on peptides, J. Phys. Chem. B, 105 (2001) 6474-6487.

[55] J.M. Hayes, J.C. Greer, D.A. Morton-Blake, A force-field description of short-range repulsions for high density alkane molecular dynamics simulations, J. Comput. Chem., 25 (2004) 1953-1966.

[56] B. Marten, K. Kim, C. Cortis, R.A. Friesner, R.B. Murphy, M.N. Ringnalda, D. Sitkoff, B. Honig, New model for calculation of solvation free energies: Correction of self-consistent reaction field continuum dielectric theory for short-range hydrogen-bonding effects, J. Phys. Chem., 100 (1996) 11775-11788.

[57] E. Harder, W. Damm, J. Maple, C.J. Wu, M. Reboul, J.Y. Xiang, L.L. Wang, D. Lupyan, M.K. Dahlgren, J.L. Knight, J.W. Kaus, D.S. Cerutti, G. Krilov, W.L. Jorgensen, R. Abel, R.A. Friesner, OPLS3: A Force Field Providing Broad Coverage of Drug-like Small Molecules and Proteins, J. Chem. Theory Comput., 12 (2016) 281-296.

[58] Y. Li, B.T. Sutch, H.H. Bui, T.K. Gallaher, I.S. Haworth, Modeling of the Water Network at Protein-RNA Interfaces, J. Chem. Inf. Model., 51 (2011) 1347-1352.

[59] E.H. Fischer, E.G. Krebs, Muscle Phosphorylase-B, Methods Enzymol., 5 (1962) 369373.

[60] E. Kyriakis, T.G.A. Solovou, S. Kun, K. Czifrak, B. Szocs, L. Juhasz, E. Bokor, G.A. Stravodimos, A.L. Kantsadi, D.S.M. Chatzileontiadou, V.T. Skamnaki, L. Somsak, D.D. Leonidas, Probing the beta-pocket of the active site of human liver glycogen phosphorylase with 3-(C-beta-D-glucopyranosyl)-5-(4-substituted-phenyl)-1, 2, 4-triazole inhibitors, Bioorg. Chem., 77 (2018) 485-493. 
[61] J.M. Hayes, V.T. Skamnaki, G. Archontis, C. Lamprakis, J. Sarrou, N. Bischler, A.L. Skaltsounis, S.E. Zographos, N.G. Oikonomakos, Kinetics, in silico docking, molecular dynamics, and MM-GBSA binding studies on prototype indirubins, KT5720, and staurosporine as phosphorylase kinase ATP-binding site inhibitors: the role of water molecules examined, Proteins, 79 (2011) 703-719.

[62] S. Saheki, A. Takeda, T. Shimazu, Assay of inorganic phosphate in the mild $\mathrm{pH}$ range, suitable for measurement of glycogen phosphorylase activity, Anal. Biochem., 148 (1985) 277281.

[63] T. Fischer, S.M. Koulas, A.S. Tsagkarakou, E. Kyriakis, G.A. Stravodimos, V.T. Skamnaki, P.G.V. Liggri, S.E. Zographos, R. Riedl, D.D. Leonidas, High consistency of structure-based design and X-Ray crystallography: design, synthesis, kinetic evaluation and crystallographic binding mode determination of biphenyl-N-acyl- $\beta$-D-glucopyranosylamines as glycogen phosphorylase inhibitors, Molecules, 24 (2019) 1322.

[64] R.J. Leatherbarrow, GraFit Version 6.0. Erithakus Software, Staines, UK., in, 2007.

[65] Agilent Technologies UK Ltd, CrysAlisPro Software system, in, Oxford, U.K., 2011.

[66] P.R. Evans, G.N. Murshudov, How good are my data and what is the resolution?, Acta Crystallogr. D Biol. Crystallogr., 69 (2013) 1204-1214.

[67] G.N. Murshudov, P. Skubak, A.A. Lebedev, N.S. Pannu, R.A. Steiner, R.A. Nicholls, M.D. Winn, F. Long, A.A. Vagin, REFMAC5 for the refinement of macromolecular crystal structures, Acta Crystallogr. D Biol. Crystallogr., 67 (2011) 355-367.

[68] A.L. Kantsadi, G.A. Stravodimos, E. Kyriakis, D.S.M. Chatzileontiadou, T.G.A. Solovou, S. Kun, E. Bokor, L. Somsak, D.D. Leonidas, van der Waals interactions govern C-beta-Dglucopyranosyl triazoles' nM inhibitory potency in human liver glycogen phosphorylase, J. Struct. Biol., 199 (2017) 57-67.

[69] F. Long, R.A. Nicholls, P. Emsley, S. Graaeulis, A. Merkys, A. Vaitkus, G.N. Murshudov, AceDRG: a stereochemical description generator for ligands, Acta Crystallogr. D Struct. Biol., 73 (2017) 112-122.

[70] P. Emsley, K. Cowtan, Coot: model-building tools for molecular graphics, Acta Crystallogr. D Biol. Crystallogr., 60 (2004) 2126-2132.

[71] R.P. Joosten, F. Long, G.N. Murshudov, A. Perrakis, The PDB_REDO server for macromolecular structure model optimization, I.U.Cr.J. , 1 (2014) 213-220.

[72] V.B. Chen, W.B. Arendall, 3rd, J.J. Headd, D.A. Keedy, R.M. Immormino, G.J. Kapral, L.W. Murray, J.S. Richardson, D.C. Richardson, MolProbity: all-atom structure validation for macromolecular crystallography, Acta Crystallogr. D Biol. Crystallogr., 66 (2010) 12-21.

[73] S.J. Hubbard, J.M. Thornton, NACCESS. Department of Biochemistry and Molecular Biology, University College, London, (1993).

[74] S. McNicholas, E. Potterton, K.S. Wilson, M.E. Noble, Presenting your structures: the CCP4mg molecular-graphics software, Acta Crystallogr. D Biol. Crystallogr., 67 (2011) 386394.

[75] H.M. Berman, J. Westbrook, Z. Feng, G. Gilliland, T.N. Bhat, H. Weissig, I.N. Shindyalov, P.E. Bourne, The Protein Data Bank, Nucleic Acids Res., 28 (2000) 235-242.

[76] A.L. Kantsadi, J.M. Hayes, S. Manta, V.T. Skamnaki, C. Kiritsis, A.M. Psarra, Z. Koutsogiannis, A. Dimopoulou, S. Theofanous, N. Nikoleousakos, P. Zoumpoulakis, M. Kontou, G. Papadopoulos, S.E. Zographos, D. Komiotis, D.D. Leonidas, The sigma-hole phenomenon of halogen atoms forms the structural basis of the strong inhibitory potency of C5 halogen substituted glucopyranosyl nucleosides towards glycogen phosphorylase $b$, ChemMedChem, 7 (2012) 722-732. 